\title{
Watt-level ultrafast laser inscribed thulium waveguide lasers
}

\author{
Esrom Kifle $^{\text {a }}$, Pavel Loiko ${ }^{\mathrm{b}}$, Carolina Romero ${ }^{\mathrm{c}}$, \\ Javier Rodríguez Vázquez de Aldana ${ }^{c}$, Magdalena Aguiló ${ }^{a}$, Francesc Díaz ${ }^{\text {a }}$, \\ Patrice Camy ${ }^{\mathrm{b}}$, Uwe Griebner ${ }^{\mathrm{d}}$, Valentin Petrov ${ }^{\mathrm{d}}$, Xavier Mateos ${ }^{\mathrm{a},{ }^{*}}$ \\ ${ }^{a}$ Física i Cristal-lografia de Materials i Nanomaterials (FiCMA-FiCNA)-EMaS, Dept. Química Física i Inorgànica, Universitat Rovira i Virgili (URV), \\ Campus Sescelades, E-43007, Tarragona, Spain \\ ${ }^{\mathrm{b}}$ Centre de Recherche sur les Ions, les Matériaux et la Photonique (CIMAP), UMR 6252 CEA-CNRS-ENSICAEN, Université de Caen, 6 Boulevard du \\ Maréchal Juin, 14050, Caen Cedex 4, France \\ ${ }^{\mathrm{c}}$ Aplicaciones del Láser y Fotónica, University of Salamanca, 37008, Salamanca, Spain \\ ${ }^{\mathrm{d}}$ Max Born Institute for Nonlinear Optics and Short Pulse Spectroscopy, Max-Born-Str. 2a, D-12489, Berlin, Germany
}

\section{A B S T R A C T}

We report on the first watt-level ultrafast laser inscribed Thulium waveguide (WG) lasers. Depressed-index buried channel WGs with a circular cladding (type III) are produced in monoclinic Tm ${ }^{3+}: \mathrm{KLu}\left(\mathrm{WO}_{4}\right)_{2}$ crystals. Laser operation is achieved under conventional $\left({ }^{3} \mathrm{H}_{6} \rightarrow{ }^{3} \mathrm{H}_{4}\right)$ and in-band $\left({ }^{3} \mathrm{H}_{6} \rightarrow{ }^{3} \mathrm{~F}_{4}\right)$ pumping. In the former case, employing a Raman fiber laser emitting at $1679 \mathrm{~nm}$ as pump, the continuous-wave Tm channel WG laser generated $1.37 \mathrm{~W}$ at $1915-1923 \mathrm{~nm}$ with a record-high slope efficiency of $82.7 \%$ (with respect to the absorbed pump power), a threshold of only 17 $\mathrm{mW}$ and a spatially single-mode output with linear polarization. The WG propagation losses were $0.2 \pm 0.3 \mathrm{~dB} / \mathrm{cm}$. Passive Q-switching of Tm channel WG lasers is achieved using $\mathrm{Cr}^{2+}: \mathrm{ZnS}$ and $\mathrm{Cr}^{2+}: \mathrm{ZnSe}$ saturable absorbers. With $\mathrm{Cr}^{2+}: \mathrm{ZnS}$, record-short pulses of $2.6 \mathrm{~ns} / 6.9 \mu \mathrm{J}$ at a repetition rate of $8.0 \mathrm{kHz}$ were generated. The developed WGs are promising for compact GHz mode-locked lasers at $\sim 2 \mu \mathrm{m}$.

\section{Introduction}

Waveguide (WG) lasers represent an important component of integrated photonic circuits [1]. They are compatible with optical fibers and various on-chip devices leading to applications in the fields of optical sensing, on-chip spectroscopy, microfluidics, telecom, medicine and soft material processing. According to their geometry, active WGs can be classified into planar and channel devices. In planar WG lasers, the mode confinement by index-guiding is ensured only in one direction (orthogonal to the plane of the active layer) [2]. In channel WGs, it is provided in two directions leading to a well-defined index profile and, typically, single-transverse-mode operation [3]. Channel WGs have the benefits of small mode areas leading to high intracavity light intensity, low laser threshold, good spatial beam quality and high efficiency due to the good overlap of pump and laser modes. Practical advantages include also their compact and robust design, and compatibility with fiber technology.

The eye-safe spectral range of $\sim 2 \mu \mathrm{m}$ contains absorption lines of several relevant bio- and atmospheric molecules such as $\mathrm{H}_{2} \mathrm{O}$, $\mathrm{CO}_{2}$, $\mathrm{N}_{2} \mathrm{O}$ or $\mathrm{NH}_{3}$. Thus, channel WG lasers emitting continuous-wave (CW) and pulsed laser radiation at these wavelengths are of particular interest for bio-sensing, on-board ice sensing and wind mapping, as well as surgery of soft tissues [4]. Such compact lasers can be also used as seed sources for WG and fiber amplifiers. Typically, laser emission at $\sim 2 \mu \mathrm{m}$ in WG lasers is achieved using trivalent rare-earth

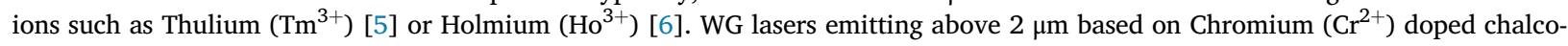
genides (ZnS, ZnSe) are known as well [7].

\footnotetext{
* Corresponding author.

E-mail address: xavier.mateos@urv.cat (X. Mateos).
} 
The Thulium ion (electronic configuration: [Xe] $4 \mathrm{f}^{12}$ ) features emission at $\sim 2 \mu \mathrm{m}$ on the ${ }^{3} \mathrm{~F}_{4} \rightarrow{ }^{3} \mathrm{H}_{6} 4 \mathrm{f}-4 \mathrm{f}$ transition [8]. Due to the typically large Stark splitting of the ground-state $\left({ }^{3} \mathrm{H}_{6}\right)$ and strong electron-phonon coupling located at the end of the lanthanide series, $\mathrm{Tm}^{3+}$-doped materials feature broad emission spectra. A conventional way to excite $\mathrm{Tm}^{3+}$ ions is to use the intense ${ }^{3} \mathrm{H}_{6} \rightarrow{ }^{3} \mathrm{H}_{4}$ transition, Fig. 1(a), spectrally located at $\sim 0.8 \mu \mathrm{m}$. Furthermore, the phonon-assisted cross-relaxation (CR) energy-transfer process that becomes efficient even at moderate $\mathrm{Tm}^{3+}$ doping levels [9], $\operatorname{Tm}_{1}\left({ }^{3} \mathrm{H}_{4}\right)+\mathrm{Tm}_{2}\left({ }^{3} \mathrm{H}_{6}\right) \rightarrow \operatorname{Tm}_{1}\left({ }^{3} \mathrm{~F}_{4}\right)+\mathrm{Tm}_{2}\left({ }^{3} \mathrm{~F}_{4}\right)$, leads to two excitations into the upper laser level thus enhancing the laser slope efficiency over the Stokes limit and reducing the heat load. Efficient Tm WG lasers based on conventional pumping using high-brightness pump sources (e.g., Ti:Sapphire lasers) are known [9,10]. Van Dalfsen et al. reported on

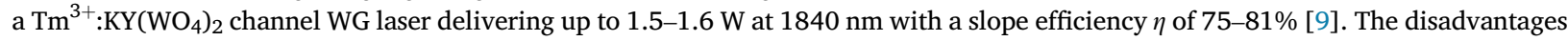
of the conventional pumping scheme are the limited power scaling capabilities and poor integration with fiber technology. High-power AlGaAs laser diodes with a suitable emission wavelength, widely used in bulk Tm lasers, have not been implemented in efficient single-transverse-mode Tm channel WG lasers so far. The latter is related to the lack of high brightness laser diodes around $800 \mathrm{~nm}$, i.e., with multi Watt emission in the transversal single mode.

Another pumping scheme for the $\mathrm{Tm}^{3+}$ ion (called resonant or in-band pumping) refers to a direct excitation to the upper laser level $\left({ }^{3} \mathrm{~F}_{4}\right)$. This scheme can result in high laser efficiency even at moderate $\mathrm{Tm}^{3+}$ concentrations. The only limiting factor here is the phononassisted energy-transfer upconversion (ETU), $\operatorname{Tm}_{1}\left({ }^{3} \mathrm{~F}_{4}\right)+\mathrm{Tm}_{2}\left({ }^{3} \mathrm{~F}_{4}\right) \rightarrow \mathrm{Tm}_{1}\left({ }^{3} \mathrm{H}_{6}\right)+\mathrm{Tm}_{2}\left({ }^{3} \mathrm{H}_{4}\right)$, a process opposite to the CR, which depopulates the upper laser level. However, for low $\mathrm{Tm}^{3+}$ doping levels, the ETU rates are weak. As a pump source for in-band pumping, one can use Raman fiber lasers operating at $\sim 1.7 \mu \mathrm{m}$. Efficient bulk in-band-pumped Tm lasers are known [13,14]. W. Yao et al. developed a Tm${ }^{3+}: \mathrm{CaYAlO}_{4}$ laser delivering $6.8 \mathrm{~W}$ at $1968 \mathrm{~nm}$ with $\eta \approx 56 \%$ [14]. There is only one report about an in-band-pumped $\mathrm{Tm}^{3+}: \mathrm{LiYF}_{4}$ waveguide laser generating $2.05 \mathrm{~W}$ at $1881 \mathrm{~nm}$ with $\eta=78.3 \%$ [15]. However, due to the weaker crystal-field in fluorides, it was not possible to operate this laser above $1.9 \mu \mathrm{m}$.

For the fabrication of Tm channel WG lasers, different methods have been used such as Liquid Phase Epitaxy (LPE) [5,16-18] with subsequent microstructuring by reaction ion $\left(\mathrm{Ar}^{+}\right)$beam etching [19] or, recently, by diamond-saw dicing [20,21], direct bonding [22], ion diffusion [23] or reactive co-sputtering [24]. Only LPE-based Tm channel WG lasers have featured watt-level output performance so far, see Table 1. In recent years, another method for the fabrication of photonic microstructures in transparent dielectric materials has emerged, namely femtosecond Direct Laser Writing (fs-DLW) [3,25], also referred as Ultrafast Laser Inscription (ULI). It is based on the formation of a strongly localized, permanent and thermally stable variation of the refractive index $(n)$ in the material volume by a tightly focused fs laser radiation. The light-guiding is then ensured by a refractive index difference $\Delta n$ between the laser damage tracks and the unmodified (bulk) material. The $\Delta n$ can be both positive (guiding within the damage tracks, type I structures, typically observed in glasses [26]) or negative (guiding between the damage tracks, type II or type III structures) depending on the material.

Fs-DLW has the advantages of short fabrication time, high precision, a great variety of the three-dimensional WG geometries and available materials (glasses, crystals or ceramics), moderate propagation losses and it is relatively simple from the technological point of view. So far, fs-DLW has been implemented for the fabrication of type II or type III channel WGs in thulium-doped glasses [27,28] and cubic crystals/ceramics [29,30], Table 1. D. Lancaster et al. achieved the best results in terms of output power using a Tm ${ }^{3+}$-doped ZBLAN glass WG with conventional pumping around $800 \mathrm{~nm}$, namely $205 \mathrm{~mW}$ at $\sim 1890 \mathrm{~nm}$ with $\eta=67 \%$ [28]. The WG propagation losses were $0.4 \pm 0.2 \mathrm{~dB} / \mathrm{cm}$. However, the obtained results are inferior compared to LPE-based WGs.

The objective of the present work is to assess the potential of fs-DLW for producing active WGs with Tm doping capable of delivering Watt-level output at $\sim 2 \mu \mathrm{m}$ with high laser efficiencies. We have employed both conventional and in-band pumping schemes. The latter has never been applied to fs-DLW Tm WGs before.

We utilized one of the advantages of fs-DLW: its applicability to various materials including low-symmetry (anisotropic) crystals. By preserving the crystallinity of the unmodified material (acting as a core), compared to the damage tracks (acting as a cladding) [32], we
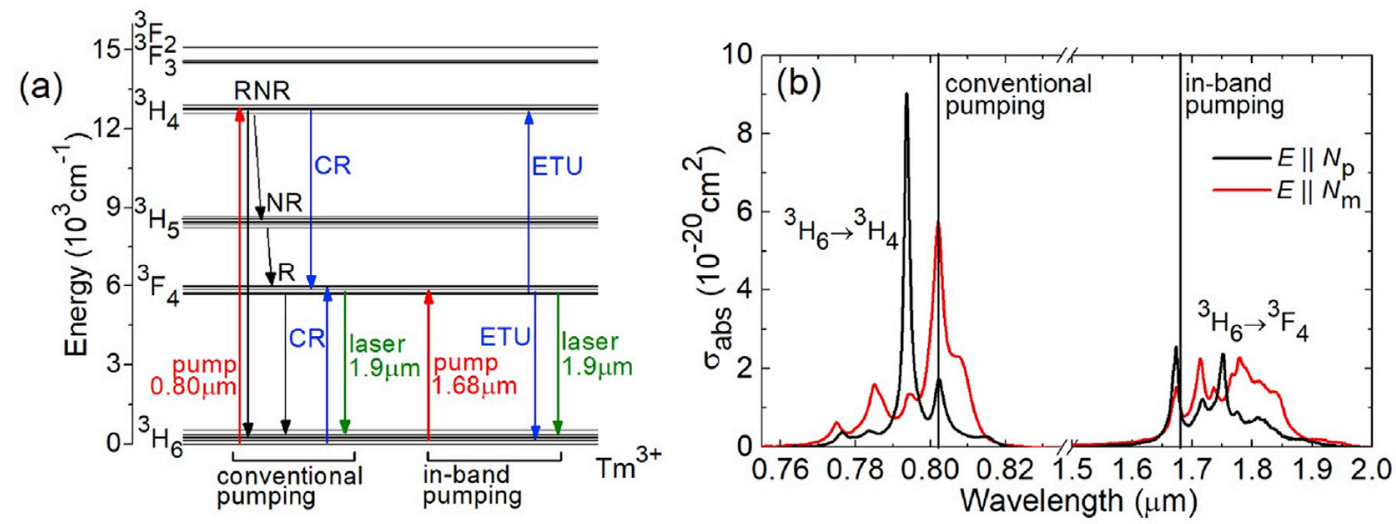

Fig. 1. (a) Energy level scheme of $\mathrm{Tm}^{3+}$ in monoclinic $\mathrm{KLu}\left(\mathrm{WO}_{4}\right)_{2}$ crystal [11] showing relevant processes: red and green arrows - pump and laser transitions, CR - cross-relaxation, NR - non-radiative relaxation, $\mathrm{R}$ - radiative relaxation, ETU - energy-transfer upconversion; (b) absorption cross-section, $\sigma_{\text {abs }}$, spectra for the ${ }^{3} \mathrm{H}_{6} \rightarrow{ }^{3} \mathrm{H}_{4}$ and ${ }^{3} \mathrm{H}_{6} \rightarrow{ }^{3} \mathrm{~F}_{4}$ transitions of $\mathrm{Tm}^{3+}$ in $\mathrm{KLu}\left(\mathrm{WO}_{4}\right)_{2}$ [12]. The pump wavelengths are indicated by the vertical lines. The light polarization is $\boldsymbol{E} \| N_{\mathrm{p}}$ and $\boldsymbol{E} \| N_{\mathrm{m}}$. 
Table 1

Output characteristics* of thulium channel waveguide lasers fabricated by liquid phase epitaxy (LPE) and femtosecond direct laser writing (DLW).

\begin{tabular}{|c|c|c|c|c|c|c|c|c|}
\hline Method & Material & $\lambda_{\mathrm{P}}, \mathrm{nm}$ & $P_{\mathrm{th}}, \mathrm{mW}$ & $P_{\text {out }}, \mathrm{W}$ & $\eta, \%$ & $\lambda_{\mathrm{L}}, \mathrm{nm}$ & $\eta_{\text {coupl }}, \%$ & Ref. \\
\hline \multirow[t]{3}{*}{ LPE } & $\mathrm{Tm}: \mathrm{KY}\left(\mathrm{WO}_{4}\right)_{2}$ & 794 & 50 & $1.5-1.6$ & $81-75$ & 1840 & 90 & [9] \\
\hline & Tm:LiYF 4 & 783 & 70 & 1.30 & 80 & 1880 & 87 & [20] \\
\hline & & 1679 & 12 & 2.05 & 78.3 & 1881 & 86.5 & [15] \\
\hline \multirow[t]{6}{*}{ DLW } & Tm:ZBLAN & 792 & 12 & 0.21 & 67 & 1890 & 79 & [28] \\
\hline & $\mathrm{Tm}: \mathrm{Y}_{3} \mathrm{Al}_{5} \mathrm{O}_{12}$ & 800 & 312 & 0.09 & 27 & 1985 & 20 & [29] \\
\hline & $\mathrm{Tm}: \mathrm{Lu}_{2} \mathrm{O}_{3}$ & 796 & 50 & 0.08 & 7 & 1942 & 40 & [30] \\
\hline & $\mathrm{Tm}: \mathrm{KLu}\left(\mathrm{WO}_{4}\right)_{2}$ & 802 & 52 & 0.17 & 37.8 & 1847 & 83 & [31] \\
\hline & & 802 & 170 & 1.07 & 62.4 & 1828-1855 & 77.1 & $* *$ \\
\hline & & 1679 & 17 & 1.37 & 82.7 & 1915-1923 & $\sim 77$ & $* *$ \\
\hline
\end{tabular}

$* \lambda_{\mathrm{P}}-$ pump wavelength, $P_{\mathrm{th}}-$ laser threshold, $\eta$ - slope efficiency ( $v s$. absorbed pump power), $P_{\text {out }}-$ output power, $\lambda_{\mathrm{L}}-$ laser wavelength, $\eta_{\text {coupl }}-$ pump coupling efficiency. The best results are selected from multiple reports on the same material.

$* *$ This work.

were able to explore the beneficial anisotropic spectroscopic properties of low-symmetry crystals. In particular, we used the monoclinic potassium lutetium double tungstate, $\mathrm{Tm}^{3+}: \mathrm{KLu}\left(\mathrm{WO}_{4}\right)_{2}$, which is known for efficient bulk laser operation at $\sim 2 \mu \mathrm{m}$ in the continuous-wave [33,34], passively Q-switched [35-37] and mode-locked [38] regimes. Thin-disk lasers based on this laser material are also known [39]. The crystal features intense and broad spectral bands (absorption and emission) with polarized light, easy Tm ${ }^{3+}$ doping, strong CR and weak luminescence quenching [12]. It is thus very attractive for both conventional and in-band pumping; see the

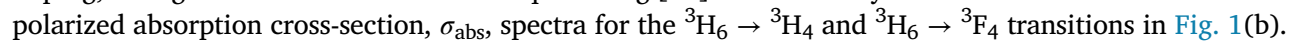

$\mathrm{KLu}\left(\mathrm{WO}_{4}\right)_{2}$ belongs to the crystal family of monoclinic double tungstates (MDTs) with a general chemical formula $\left.\mathrm{KRE}(\mathrm{WO})_{2}\right)_{2}$ (abbreviated: KREW, where RE $=\mathrm{Gd}$, Y or Lu is a host-forming cation). So far, these crystals were recognized as excellent laser host materials for doping with such rare-earth ions $\left(\mathrm{RE}^{3+}\right)$ as $\mathrm{Yb}^{3+}[40-44], \mathrm{Tm}^{3+}[33-38,45]$ and Ho ${ }^{3+}$ [46-49]. The advantages of $\mathrm{RE}^{3+}$-doped MDTs are the following: (i) high $\mathrm{RE}^{3+}$ doping levels (up to stoichiometric compositions) with minimum lattice distortions; (ii) ordered structure, i.e., a single crystallographic site for the $\mathrm{RE}^{3+}$ ions $\left(\mathrm{C}_{2}\right)$, (iii) long $\mathrm{RE}^{3+}-\mathrm{RE}^{3+}$ interatomic distances leading to a weak luminescence quenching; (iv) high luminescence quantum yields and weak non-radiative relaxation from the emitting states of the considered $\mathrm{RE}^{3+}$ ions; (v) strong anisotropy of optical and spectroscopic properties for polarized light; (vi) Raman activity. As for the thermal properties, the thermal conductivity of MDT is moderate $\left.\left(\kappa \sim 3.5 \mathrm{Wm}^{-1} \mathrm{~K}^{-1} \text { for } \mathrm{KLu}_{(\mathrm{WO}}\right)_{2}\right)[50]$. The thermo-optical effects in MDTs can be greatly suppressed owing to their "athermal" behavior [51,52], i.e., a mutual compensation of contributions to the variation of the optical path length arising from the negative thermo-optic coefficients $(\mathrm{d} n / \mathrm{d} T<0)[53]$ and positive thermal expansion [54]. These properties lead to a weak, positive and nearly spherical thermal lens for certain crystal orientations with a reduced effect on the laser mode [55-59].

Prior to the present work, there existed studies on ultrafast laser direct written channel WGs in monoclinic double tungstate crystals (see Section 3.4). In particular, fs-DLW buried channel WGs in the monoclinic $\left.\mathrm{Tm}^{3+}: \mathrm{KLu}_{(\mathrm{WO}}\right)_{2}$ crystal were first reported in Ref. [60].

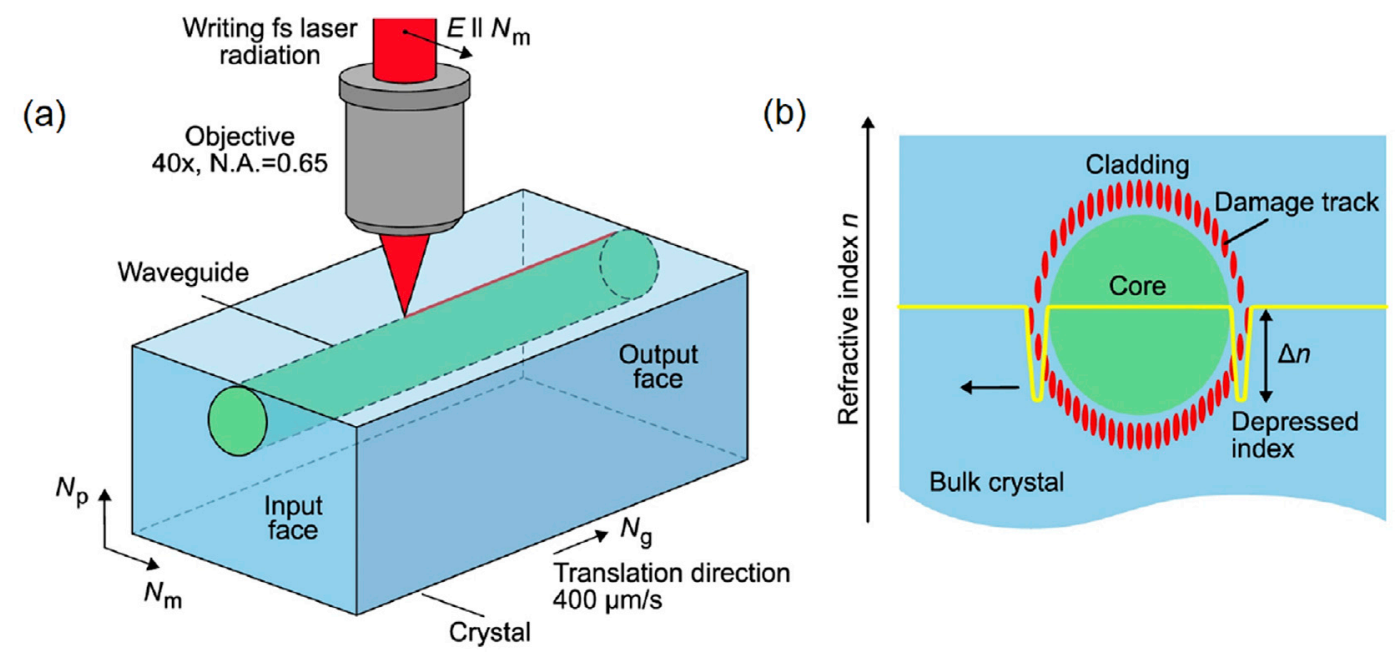

Fig. 2. (a) Femtosecond Direct Laser Writing of channel buried waveguides in a bulk Tm:KLuW crystal; (b) illustration of the geometry of a depressed-index waveguide with a circular cladding (type III structure, end-facet view). 


\section{Direct laser writing and waveguide laser setup}

\subsection{Fabrication and characterization of waveguides}

As a gain material, we used the monoclinic (sp. gr. $\mathrm{C}_{2 \mathrm{~h}}{ }_{2 \mathrm{C}} \mathrm{C} 2 / \mathrm{c}$ ) $\mathrm{Tm}^{3+}: \mathrm{KLu}\left(\mathrm{WO}_{4}\right)_{2}$ crystal (shortly Tm:KLuW). It was grown by the Top-Seeded Solution Growth (TSSG) Slow-Cooling method using potassium ditungstate $\left(\mathrm{K}_{2} \mathrm{~W}_{2} \mathrm{O}_{7}\right)$ as a solvent and a [010]-oriented seed [12]. The Tm ${ }^{3+}$ doping level was 3 at.\% (ion density: $N_{\mathrm{Tm}}=2.15 \times 10^{20} \mathrm{~cm}^{-3}$ ). Tm:KLuW is an optically biaxial crystal and it was oriented in the frame of the mutually orthogonal optical indicatrix axes $N_{\mathrm{p}}, N_{\mathrm{m}}$ and $N_{\mathrm{g}}$ (the corresponding refractive indices follow the relation $n_{\mathrm{p}}<n_{\mathrm{m}}<n_{\mathrm{g}}$ ). A rectangular sample was cut for light propagation along the $N_{\mathrm{g}}$-axis $\left(N_{\mathrm{g}}\right.$-cut) to utilize the advantageous thermo-optical [51,55] and spectroscopic [11] properties for this crystal orientation. The sample thickness $(t)$ was 3.00 mm and its aperture was $3.10\left(N_{\mathrm{m}}\right) \times 2.85\left(N_{\mathrm{p}}\right) \mathrm{mm}^{2}$. Its input, output and top surfaces were polished to laser-grade quality (prior to the inscription of the WGs) and remained uncoated.

Depressed-index buried channel WGs with a circular cladding were fabricated in bulk Tm:KLuW crystals by fs-DLW [60], see the scheme in Fig. 2(a). As a laser source, we used a Ti:Sapphire regenerative amplifier (Spitfire, Spectra-Physics) delivering 120 fs pulses at a central wavelength of $795 \mathrm{~nm}$ with a repetition rate of $1 \mathrm{kHz}$. The pulse energy incident on the sample was attenuated using a set of a half-wave $(\lambda / 2)$ plate, a calibrated neutral density filter and a linear polarizer. A $40 \times$ microscope objective (numerical aperture: N.A. $=$ $0.65)$ was used to focus the femtosecond laser radiation into the sample through the polished top face $\left(N_{\mathrm{m}} \times N_{\mathrm{g}}\right)$. To produce the damage tracks, the sample was translated in the horizontal direction (along the $N_{\mathrm{g}}$-axis) with a speed of $400 \mu \mathrm{m} / \mathrm{s}$. The incident pulse energy on the sample was $\sim 57 \mathrm{~nJ}$. The damage tracks were continuous and they were written through the entire sample length thus reaching the polished input and output surfaces. No repolishing of the sample end-facets was applied after completing the fs-DLW process. The polarization of the femtosecond radiation $\left(\boldsymbol{E} \| N_{\mathrm{m}}\right)$ was orthogonal to the writing direction [32] to avoid anisotropic effects related to the birefringence of MDTs. The writing parameters were optimized in a set of previous test experiments.

The photograph of the sample during fs-DLW is shown in Fig. 3.

The line scan procedure was repeated at different depths and lateral positions of the crystal to fabricate a barrel-shaped WG, Fig. 2(b). It consisted of an unmodified core surrounded by a ring-shaped cladding (diameter: $40 \mu \mathrm{m}$ ) containing 48 damage tracks. The bottom-up writing approach was implemented to ensure that the incoming pulses are not blocked or distorted by the previously written tracks. The axis of the WG was located at a depth of $\sim 120 \mu \mathrm{m}$ below the crystal surface. The tracks had a lateral separation of $2 \mu \mathrm{m}$. Their size was $\sim 1 \times 6 \mu \mathrm{m}^{2}$ along the horizontal and vertical directions.

The end-facet and top-surface of the sample were inspected using a confocal laser microscope (model LSM 710, Carl Zeiss) equipped with a blue laser diode $(\lambda=405 \mathrm{~nm})$ and a polarizer, Fig. 4 . All the studies were performed in transmission mode with polarized light. When observing the end-facet, a dark ring of damage tracks below the crystal surface representing the cladding is seen, Fig. 4(a). No cracks surrounding the cladding are visible for the selected pulse energy. The inner part of the WG is darker because of the scattering at the damage tracks. Similarly, observing the WG from the top crystal surface, Fig. 4(b), a dark barrel-shaped cladding is visible in the pristine bulk volume. The cladding has a periodic net-like surface.

The modification of the material in the irradiated regions was confirmed by $\mu$-Raman spectroscopy. This method is well suited to characterize the structural modifications induced by the fs pulses and to study the integrity of the inherent crystal structure at the WG core. For the mapping, a Renishaw inVia Reflex confocal Raman microscope equipped with an $\operatorname{Ar}^{+}$laser $\left(\lambda_{\text {exc }}=514 \mathrm{~nm}\right)$ and a $50 \times$ Leica objective was used. A set of a $\lambda / 2$ plate and a polarizer were used to determine the polarization state of the incident and scattered light. The measurement geometry was $g(j k) \bar{g}$, where $j, k=p, m$ for the overview polarized Raman spectra, Fig. 5 , and $g(m m) \bar{g}$ for the $\mu$-Raman mapping. Here and below, we use the Porto's notations [61] for polarized Raman spectroscopy, i.e., $i(j k) \bar{l}$, where the indices $i$ and $l$ stand for the directions of propagation of the excitation and the back-scattered (detected) light, respectively, and the indices $j$ and $k$ indicate the corresponding polarization states. For simplicity, we use the labels $p, m, g$ for the optical indicatrix axes $N_{\mathrm{p}}, N_{\mathrm{m}}, N_{\mathrm{g}}$, respectively. For

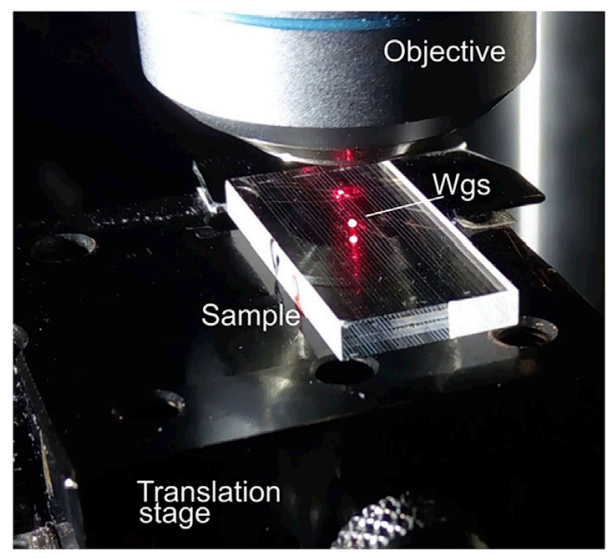

Fig. 3. Photograph of a Tm:KLuW sample under femtosecond Direct Laser Writing. The red laser serves as a laser pointer. 
End-facet view

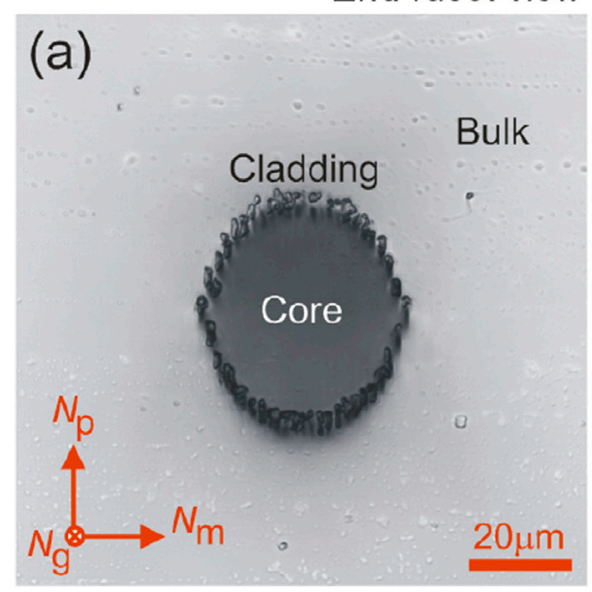

Top view

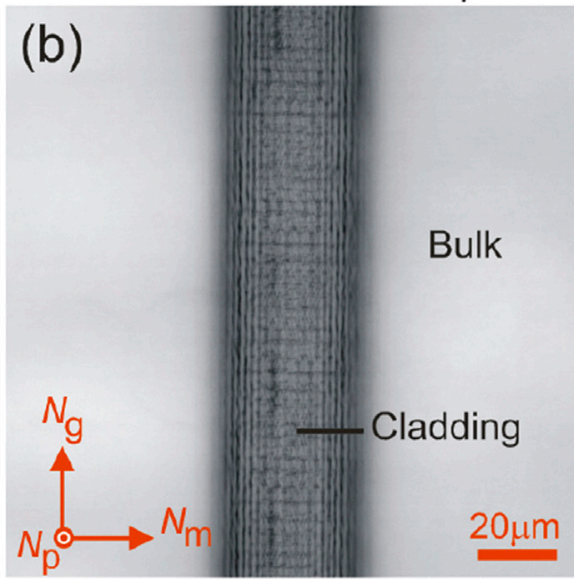

Fig. 4. Confocal laser microscope images of a buried channel waveguide in Tm:KLuW produced by femtosecond Direct Laser Writing: (a) end-facet view, (b) top view. Transmission mode, $\lambda=405 \mathrm{~nm}$, polarized light: (a) P $\| N_{\mathrm{p}}$, (b) P $\| N_{\mathrm{g}}$.

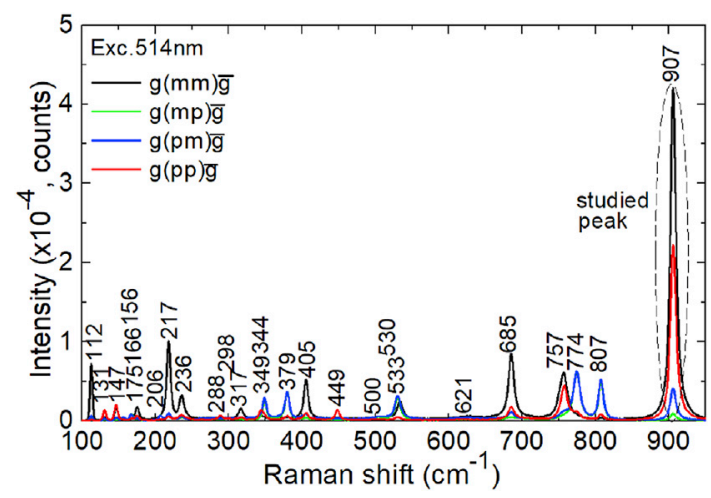

Fig. 5. Polarized Raman spectra of the 3 at.\% Tm:KLuW crystal. The measurement geometry is $g(j k) \bar{g}$ for $j, k=p, m$ (Porto's notations), $\lambda_{\text {exc }}=$ $514 \mathrm{~nm}$.

the $\mu$-Raman mapping, we selected the most intense vibration of $\mathrm{KLuW}$, centered at $\sim 907 \mathrm{~cm}^{-1}$ and assigned as $\nu(\mathrm{W}-\mathrm{O}) / \nu_{1}$ (internal mode) [12]. It is related to the $\mathrm{W}-\mathrm{O}$ stretching vibrations in the distorted $\mathrm{WO}_{6}$ octahedrons.

During the measurement, a high precision motorized 3D-stage was used to control the position of the sample. Initially, the end-facet of the WG was aligned to be at the focus of the laser. The sample was translated by $\sim 15 \mu \mathrm{m}$ (the measurement was performed slightly
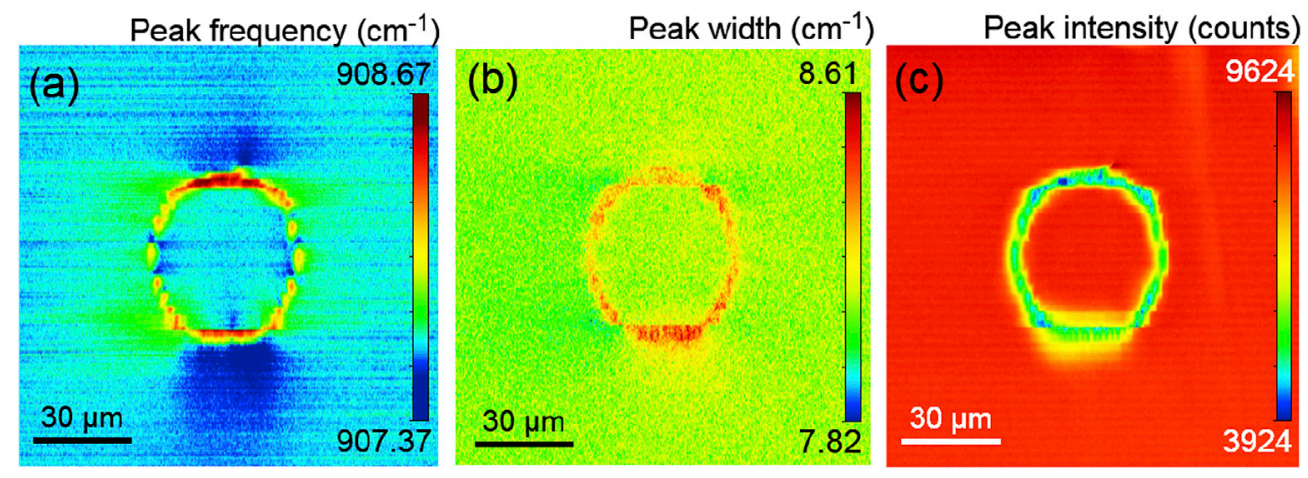

Fig. 6. Micro-Raman mapping of a polished end-facet of the depressed-cladding buried channel WG in Tm:KLuW produced by femtosecond Direct Laser Writing: measuring the high gain $907 \mathrm{~cm}^{-1}$ phonon mode: (a) peak frequency, (b) peak width (full width at half-maximum - FWHM) and (c) peak intensity. Measurement geometry: $g(\mathrm{~mm}) g$ (Porto's notations), $\lambda_{\mathrm{exc}}=514 \mathrm{~nm}$. WG diameter: $40 \mu \mathrm{m}$. 
below the surface). The Wire 3.5TM software was used. The Raman spectra were taken with a spatial resolution of $\sim 0.4 \mu \mathrm{m}$ and a spectral resolution of $\sim 1 \mathrm{~cm}^{-1}$ over the desired area $\left(140\left(N_{\mathrm{p}}\right) \times 140\left(N_{\mathrm{m}}\right) \mu \mathrm{m}^{2}\right)$. The Raman peak was fitted using the Lorentz profile yielding the peak height (intensity), the peak position (Raman shift) and the peak width. The 2D plots of these parameters created the desired maps, Fig. 6.

In the core region, the crystalline quality of the material is well preserved, as indicated by almost unchanged Raman response as compared to that from the pristine bulk crystal surrounding the WG. Thus, fs-DLW is expected to maintain the beneficial anisotropic optical and spectroscopic properties of the crystal. For the irradiated regions forming the depressed-index cladding, a decreased Raman intensity, broadening of the peak and a shift of its position to higher frequencies are observed. These findings are an indication of a partial amorphization of the material (a decrease in its crystallinity - a degree of structural order, i.e., the lack of lattice defects, imperfections and structure disorder). The existence of a residual anisotropic stress field is evident from the observed phonon energy shift outside the WG cladding [62], see Fig. 6(a). This stress field leads to the stress-induced birefringence via the photo-elastic effect [63] and favors the polarization response of the WG.

For $\mathrm{Tm}^{3+}: \mathrm{KLuW}$, because of the anisotropy of its spectroscopic properties, it is desirable to work (both in absorption and emission) with light polarization $\boldsymbol{E} \| N_{\mathrm{m}}$. The corresponding refractive index of the bulk (undoped) KLuW crystal is $n_{\mathrm{m}}=1.9927$ at the wavelength of $1.9 \mu \mathrm{m}$ [64]. This value is calculated using the Sellmeier formulas based on the experimental data on the dispersion of the principal refractive indices. The latter were determined in Ref. [64] by the minimum deviation method using oriented prisms. For the fabricated micro-structures, the waveguiding properties were ensured by a decrease of the refractive index in the cladding, $\Delta n=n_{\text {cladding }}-n_{\text {core }} \approx$ $-0.6 \times 10^{-3}$ [32]. In Ref. [32], this value was estimated at the wavelength of $\sim 1.84 \mu \mathrm{m}$ using the measured laser mode divergence out of a buried channel WG inscribed in a 3 at.\% Tm:KLuW crystal. Thus, the fabricated WGs are classified as type III fs-DLW structures (or depressed-cladding WGs, contrary to another known geometry also based on depressed refractive index, type II, but relying on a double-track scheme and a stress-induced refractive increase at the waveguide core) [3].

Depressed-cladding WGs were first reported by Okhrimchuk et al. for $\mathrm{Nd}^{3+}$ :YAG crystals $[65,66]$. Later, such structures were fabricated in various materials doped with various $\mathrm{RE}^{3+}$ ions, such as (i) $\mathrm{Nd}^{3+}$ [67-71] and (ii) $\mathrm{Yb}^{3+}$ [72-74], both applied for laser emission at $\sim 1 \mu \mathrm{m}$ (iii) $\mathrm{Er}^{3+}$ [75-77], the laser operation was achieved in the visible, at $\sim 0.55 \mu \mathrm{m}$, using an upconversion pumping scheme, and in the near-infrared, at $\sim 1.5 \mu \mathrm{m}$; $\mathrm{Pr}^{3+}[78,79]$, for red laser emission at $\sim 0.6-0.7 \mu \mathrm{m}$; $\mathrm{Ho}^{3+}$ [80-82], for near-mid-infrared emissions at $\sim 2.1 \mu \mathrm{m}$ and $\sim 2.9 \mu \mathrm{m}$. The results for $\mathrm{Tm}^{3+}$-doped type III WGs are discussed in the Introduction section. Moreover, such a WG geometry was implemented for transition-metal-doped (e.g., $\mathrm{Cr}^{4+}, \mathrm{Cr}^{2+}, \mathrm{Fe}^{2+}$ ); materials used both as saturable absorbers [83] and gain media [84,85].

\subsection{Laser set-up}

The scheme of the WG laser is shown in Fig. 7. The WG sample was mounted on a passively-cooled glass (BK7) holder. The linear laser cavity was composed of a flat pump mirror (PM) coated for high transmission (HT) at the pump wavelengths ( $T=96 \%$ at $0.80 \mu \mathrm{m}$ and $93 \%$ at $1.68 \mu \mathrm{m}$ ) and for high reflection (HR) at $1.87-2.30 \mu \mathrm{m}$, and a set of flat output couplers (OCs) with transmission $T_{\mathrm{OC}}=$ $1.6 \% . . .50 \%$ at the laser wavelength. Operation without an OC (relying solely on the Fresnel reflection from the uncoated WG facet, equivalent to $T_{\mathrm{OC}}=89 \%$ ) was also studied. We have also employed a short-pass OC coated for HT at $1.80-1.96 \mu \mathrm{m}$ with $T_{\mathrm{OC}}$ of $2 \%$ at 2.02-2.12 $\mu \mathrm{m}$, to enforce laser oscillation above $2 \mu \mathrm{m}$. For CW operation, both PM and OC were placed as close as possible to the crystal with minimum air gaps. No index-matching liquid was used. Such liquids, under high pump power, might burn and damage the WG endfacets or induce coating damage to the mirrors. Thus, for the CW laser, the geometrical cavity length was $3.0 \mathrm{~mm}$.

Two pump sources were applied. The first source for conventional pumping the ${ }^{3} \mathrm{H}_{6} \rightarrow{ }^{3} \mathrm{H}_{4}$ transition was a CW Ti:Sapphire laser (model 3900S, Spectra Physics) delivering up to $3.2 \mathrm{~W}$ at $\lambda_{\mathrm{P}}=802 \mathrm{~nm}$ (emission bandwidth: $\Delta \lambda_{\mathrm{P}}<0.2 \mathrm{~nm}$ ) with $\mathrm{M}^{2} \approx 1$. The second source for in-band pumping the ${ }^{3} \mathrm{H}_{6} \rightarrow{ }^{3} \mathrm{~F}_{4}$ transition was a home-made Raman fiber laser (RFL) [86] delivering up to $4.45 \mathrm{~W}$ at $1679 \mathrm{~nm}$ $\left(\Delta \lambda_{\mathrm{P}}=1 \mathrm{~nm}\right)$ with $\mathrm{M}^{2} \approx 1$. Both lasers were linearly polarized. The pump was focused into the crystal using a spherical uncoated CaF 2 lens (focal length: $\mathrm{f}=40 \mathrm{~mm}$, transmission at the pump wavelengths: $T=93.8 \pm 0.3 \%$ ) resulting in a pump spot size at the input WG facet $2 w_{\mathrm{P}}=30 \pm 5 \mu \mathrm{m}$. The pump polarization was $\boldsymbol{E} \| N_{\mathrm{m}}$.

For the Ti:Sapphire laser, the pump coupling efficiency into the WG, $\eta_{\text {coupl }}=P_{\text {coupl }} / P_{\text {inc }}$, was determined from pump-transmission experiments at $830 \mathrm{~nm}$ (out of $\mathrm{Tm}^{3+}$ absorption) to be $77.1 \pm 1 \%$ (Fresnel losses at the uncoated WG input facet taken into account). The pump absorption at $802 \mathrm{~nm}, \eta_{\mathrm{abs}, \mathrm{NL}}=P_{\mathrm{abs}} / P_{\text {coupl }}$, was determined in a similar manner under non-lasing conditions at incident pump powers corresponding to the laser threshold $P_{\text {th }}$ for each OC (we assumed that under lasing conditions, $\eta_{\text {abs, } \mathrm{L}} \approx$ $\left.\eta_{\mathrm{abs}, \mathrm{NL}}\left(P_{\mathrm{th}}\right)\right)$. It amounted to $81-85 \pm 1 \%$, depending on the OC. Similar values were obtained from a rate-equation model accounting for

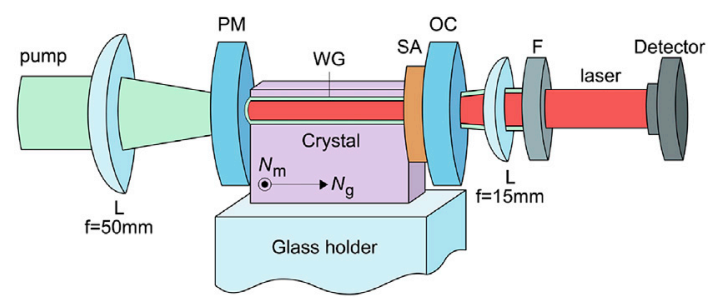

Fig. 7. Scheme of the Tm channel waveguide laser: L - lenses, PM - pump mirror, OC - output coupler, SA - saturable absorber, F - cut-off filter. 
the ground-state bleaching and CR. Note that the small-signal pump absorption calculated from the spectroscopic parameters, $\eta_{\text {abs }, 0}=1$ $-\exp \left(-\sigma^{\mathrm{P}}{ }_{\text {abs }} N_{\mathrm{Tm}} t\right)=97.5 \%$. Here, $\sigma_{\text {abs }}^{\mathrm{P}}=5.75 \times 10^{-20} \mathrm{~cm}^{2}$, cf. Fig. 1(b). Thus, the pump absorption in the WG was bleached.

For the RFL, we assumed a similar value of $\eta_{\text {coupl }}$. The pump absorption was taken at its small-signal limit, $\eta_{\text {abs }, 0(1-p a s s)}=50.8 \%\left(\sigma^{\mathrm{P}}\right.$ abs $=1.10 \times 10^{-20} \mathrm{~cm}^{2}$, Fig. 1(b)), not to overestimate the laser slope efficiency. Because of the high reflectivity of the OCs at $\sim 1.68 \mu \mathrm{m}$, the pumping was in double-pass. Thus, the total pump absorption, $\eta_{\text {abs, } 0(2 \text {-pass })}=56.1 \pm 1 \%$.

For the passive Q-switching experiments, a transmission-type SA was inserted between the crystals and the OC at a normal incidence with minimum air gaps.

The laser output after the OC was collimated using a spherical $\mathrm{CaF}_{2}$ lens ( $\mathrm{f}=15 \mathrm{~mm}$ ). A cut-off filter (FEL 900, Thorlabs) was used to filter out the residual pump. The emission spectra were measured using an optical spectrum analyzer (OSA, model AQ6375B, Yokogawa) equipped with a low-OH multimode optical fiber (core diameter: $200 \mu \mathrm{m}$, N.A. $=0.50$, length: $2 \mathrm{~m}$ ) from Thorlabs. The laser radiation was coupled into the fiber using an uncoated $\mathrm{CaF}_{2}$ lens $(\mathrm{f}=40 \mathrm{~mm})$. The spectral sensitivity of the OSA-based set-up was calibrated using a quartz iodine lamp with known spectral power distribution. The beam profile was captured using a FIND-R-SCOPE near-IR camera. The output facet of the WG was reimaged onto the camera using a short focal length $\mathrm{CaF}_{2}$ lens ( $\mathrm{f}=15 \mathrm{~mm}$ ). The pump and laser radiation were selected by a proper long-pass/short-pass filter. A scale calibration for the camera was provided by illuminating the WG with nearIR light revealing the cladding with a known size. We also used a 1951 USAF resolution test target (R1DS1, Thorlabs) placed on the position of the WG output facet to verify the scale calibration for the camera. The pulsed output was detected with a fast InGaAs photodetector (model UPD-5N-IR2-P, Alphalas, rise time: $<200 \mathrm{ps)}$ ) and an $8 \mathrm{GHz}$ digital oscilloscope (DSA70804B, Tektronix).

\subsection{Saturable absorbers}

For the passive Q-switching experiments, several SAs based on $\mathrm{Cr}^{2+}$-doped chalcogenides (ZnS and ZnSe) were used. They are wellknown for passive Q-switching of bulk Tm lasers [87-89]. They provide (i) a broad and intense absorption in the near-IR related to the ${ }^{5} \mathrm{~T}_{2} \rightarrow{ }^{5} \mathrm{E}\left({ }^{5} \mathrm{D}\right)$ transition of $\mathrm{Cr}^{2+}$ ions in tetrahedral $\left(T_{\mathrm{d}}\right)$ sites, Fig. 8(a); (ii) high ground-state absorption (GSA) cross-sections, $\sigma_{\mathrm{GSA}}$, (iii) low excited-state absorption and (iv) acceptable laser-induced damage threshold (LIDT) [90-92]. At the laser wavelength of $\sim 1.84 \mu \mathrm{m}$, the $\sigma_{\mathrm{GSA}}$ are $0.62 \times 10^{-18} \mathrm{~cm}^{2}$ (for $\mathrm{Cr}^{2+}: \mathrm{ZnS}$ ) and $0.95 \times 10^{-18} \mathrm{~cm}^{2}$ (for $\mathrm{Cr}^{2+}: \mathrm{ZnSe}$ ).

The thickness of the SAs $\left(t_{\mathrm{SA}}\right)$ was about 1.0 and $2.2 \mathrm{~mm}$ for $\mathrm{Cr}^{2+}: \mathrm{ZnSe}$ and $\mathrm{Cr}^{2+}: \mathrm{ZnS}$, respectively, and their small-signal (unsaturated) transmission at $1.84 \mu \mathrm{m} T_{\mathrm{SA}}$ was $98.0 \ldots 64.3 \%$, Fig. 8(b). Both faces of the SAs were AR-coated at the laser wavelength to reduce the insertion losses.

The passive Q-switching experiments were performed using the conventional pumping at $800 \mathrm{~nm}$ in order to avoid excessive heating of the SA by the residual (non-absorbed) pump that may lead to unstable operation. Only OCs with high transmission $\left(T_{\mathrm{OC}}=20 \%\right.$ and $50 \%$ ) were used to avoid damage to the optical components due to the high intracavity laser fluence.

\section{Continuous-wave lasers}

\subsection{Conventional pumping}

At first, we used conventional pumping (to the ${ }^{3} \mathrm{H}_{4}$ state, $\lambda_{\mathrm{P}}=802 \mathrm{~nm}$ ). The input-output characteristics of the Tm WG laser are shown in Fig. 9(a). For the "standard" OCs, the maximum output power reached for $T_{\mathrm{OC}}=50 \%, 1.07 \mathrm{~W}$ at $1828-1855 \mathrm{~nm}$ with a slope efficiency $\eta$ of $62.4 \%$ (with respect to the absorbed pump power, $P_{\text {abs }}$ ). The laser threshold was at $P_{\text {abs }}=170 \mathrm{~mW}$ and the optical-tooptical conversion efficiency $\eta_{\text {opt }}$ was $38.3 \%$ ( $v$ s. the incident pump power, $P_{\text {inc }}$ ). For lower output coupling, the laser performance gradually deteriorated.

The laser emission spectra are shown in Fig. 9(b). They are broad and contain multiple lines due to (i) the broad gain spectra of $\mathrm{Tm}^{3+}: \mathrm{KLuW}$ and (ii) etalon (Fabry-Perot) effects at the crystal-mirror interfaces. As the output coupling decreased, the central laser
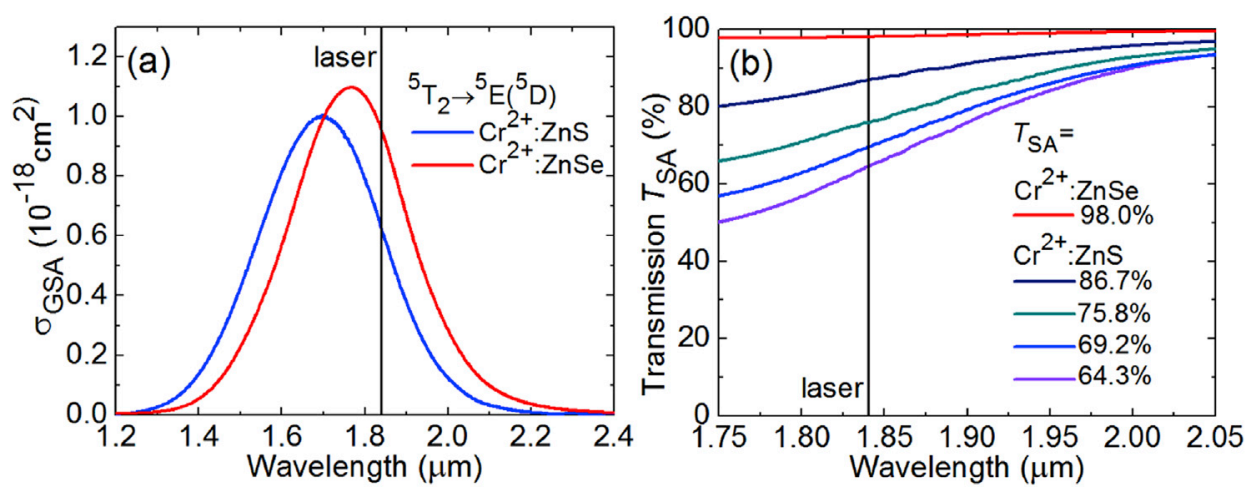

Fig. 8. (a) Ground-state-absorption (GSA) cross-section, $\sigma_{\mathrm{GSA}}$, spectra of $\mathrm{Cr}^{2+}: \mathrm{ZnS}$ and $\mathrm{Cr}^{2+}: \mathrm{ZnSe}$ (this work); (b) the small-signal transmission ( $T_{\mathrm{SA}}$ ) spectra of the studied SAs. The vertical lines indicate the laser wavelength. 

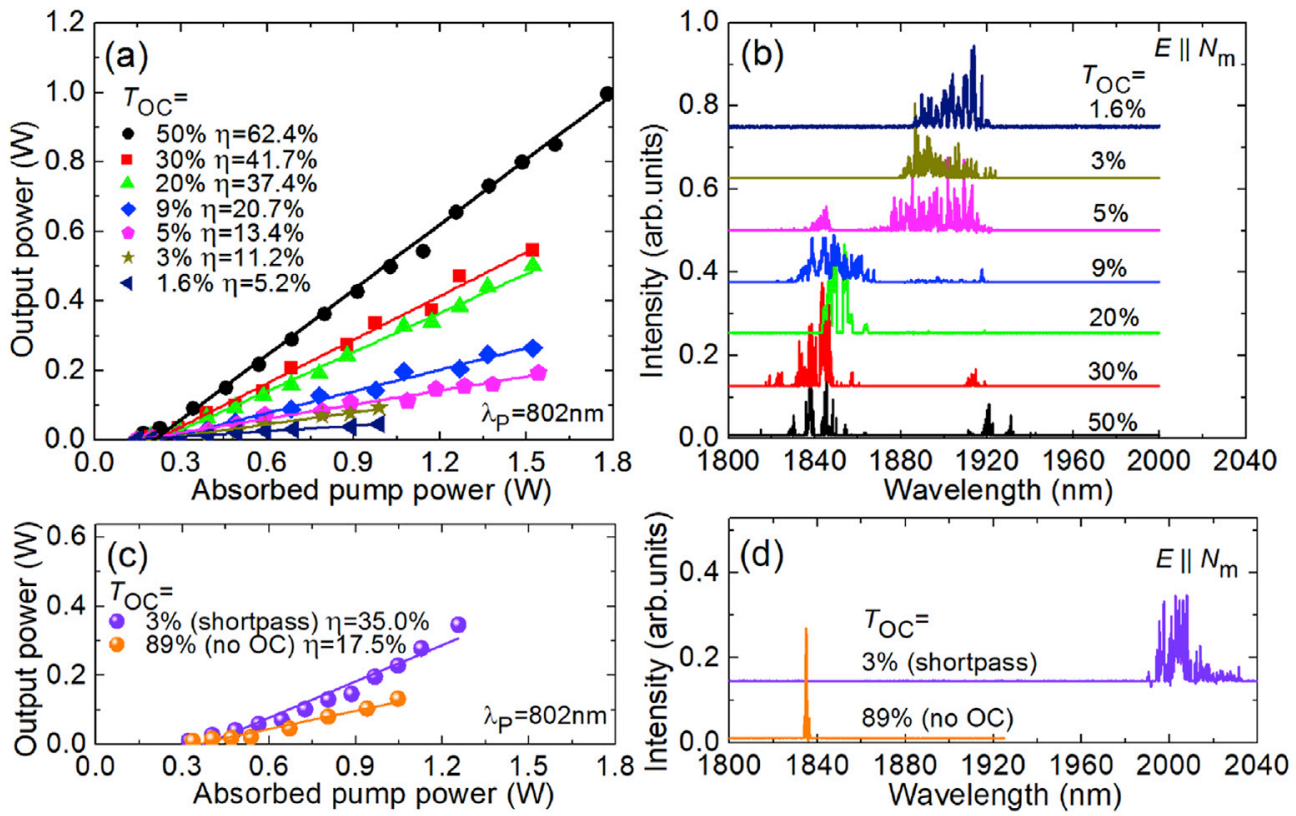

Fig. 9. Continuous-wave Tm channel WG laser with conventional pumping $\left(\lambda_{\mathrm{P}}=802 \mathrm{~nm}\right)$ : (a,c) input-output dependencies, $\eta$ - slope efficiency; (b,d) typical laser emission spectra, $P_{\mathrm{abs}}=1 \mathrm{~W}$. The laser polarization is $\boldsymbol{E} \| N_{\mathrm{m}}$.

wavelength experienced a red-shift due to the quasi-three-level nature of the ${ }^{3} \mathrm{~F}_{4} \rightarrow{ }^{3} \mathrm{H}_{6} \mathrm{Tm}^{3+}$ laser transition exhibiting reabsorption losses [12]. For the lowest $T_{\mathrm{OC}}=1.6 \%$, the emission was at $1887-1921 \mathrm{~nm}$. For $T_{\mathrm{OC}}<5 \%$, the laser operated at $\sim 1.90 \mu \mathrm{m}$ and for higher $T_{\mathrm{OC}}$, it jumped to $\sim 1.84 \mu \mathrm{m}$. This agrees with the gain spectra of $\mathrm{Tm}^{3+}: \mathrm{KLuW}$ for $\boldsymbol{E} \| N_{\mathrm{m}}$, Fig. 10.

Without an OC (effective $T_{\mathrm{OC}}$ of $89 \%$ ), the WG laser-generated an output power of $130 \mathrm{~mW}$ at $\sim 1834$ nm with a notably increased laser threshold of $335 \mathrm{~mW}$ and much lower $\eta=17.5 \%$, see Fig. 9 (c and d). This is attributed to significantly higher upconversion losses associated with high $\mathrm{Tm}^{3+}$ inversion ratios $\beta=N_{2}\left({ }^{3} \mathrm{~F}_{4}\right) / N_{\mathrm{Tm}}$. Indeed, high $\beta$ is needed to compensate for the cavity losses in this case leading to enhanced ETU.

With a short-pass OC, we achieved an output power of $350 \mathrm{~mW}$ at $1994-2032 \mathrm{~nm}$ with $\eta=35.0 \%$, Fig. 9 (c and d). The laser threshold was relatively high, $310 \mathrm{~mW}$. The longest wavelength of a purely electronic transition ${ }^{3} \mathrm{~F}_{4} \rightarrow{ }^{3} \mathrm{H}_{6}$ for Tm ${ }^{3+}: \mathrm{KLuW}$ is $1948 \mathrm{~nm}($ corresponding to a transition between the Stark sub-levels with energies 5663 and $530 \mathrm{~cm}^{-1}$, i.e., the lowest and the highest ones in the corresponding multiplets) [11]. The observed wavelengths are attributed to vibronic interaction (the electron-phonon coupling) with the low-energy phonons of the KLuW lattice, cf. Fig. 5 [93]. Such vibronic emissions have been previously observed only in bulk Tm lasers [93-95].

For all studied OCs, the laser output was linearly polarized $\left(\boldsymbol{E} \| N_{\mathrm{m}}\right)$; the polarization was naturally selected by the gain anisotropy, Fig. 10(a) [12]. The output power dependencies were linear indicating weak thermal effects. This was confirmed by applying a
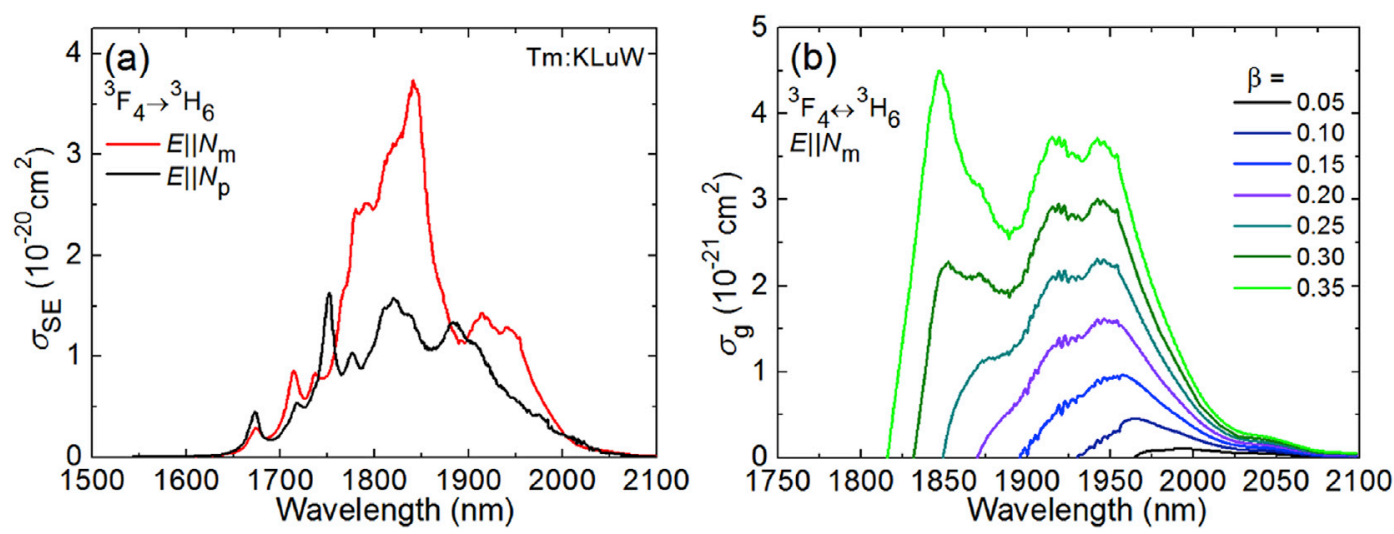

Fig. 10. Emission properties of $\mathrm{Tm}^{3+}$ ions in KLuW at $\sim 2 \mu \mathrm{m}$ (the ${ }^{3} \mathrm{~F}_{4} \leftrightarrow{ }^{3} \mathrm{H}_{6}$ transition): (a) stimulated-emission (SE) cross-sections, $\sigma_{\mathrm{SE}}$, for light polarizations $\boldsymbol{E} \| N_{\mathrm{m}}$ and $\boldsymbol{E} \| N_{\mathrm{p}}$; (b) gain cross-sections, $\sigma_{\mathrm{g}}=\beta \sigma_{\mathrm{SE}}-(1-\beta) \sigma_{\mathrm{abs}}$, for light polarization $\boldsymbol{E} \| N_{\mathrm{m}}$ and various inversion ratios $\beta=N_{2}\left({ }^{3} \mathrm{~F}_{4}\right) /$ $N_{\text {Tm }}, N_{2}$ is the population of the upper laser level. 
quasi-CW pumping (duty cycle: 1:2). No thermal fracture of the crystal around the written WGs was observed. The produced damage tracks were stable under the high-power laser irradiation and the associated heating.

For both pump and laser wavelengths, we analyzed the mode profiles at the WG output facet, Fig. 11. The pump mode, Fig. 11(a), is well confined within the cladding and it is slightly multimode. There is a weak leakage of the pump mode through the ring of the damage tracks. The laser mode, Fig. 11(b), is confined within the cladding, and the corresponding 1D intensity profiles along the horizontal (along the polarization, $\| N_{\mathrm{m}}$ ) and vertical (\| $N_{\mathrm{p}}$ ) directions are nearly Gaussian, see Fig. 11(c) (goodness of the fit: $\mathrm{R}^{2}>0.99$ ). The mode diameters (at the $1 / \mathrm{e}^{2}$ intensity level) are $2 w_{\mathrm{L}}=41.9 \pm 2 \mu \mathrm{m}$ and $39.4 \pm 2 \mu \mathrm{m}$, respectively. Thus, a good overlap between the pump and laser modes is observed.

The measured $\mathrm{M}^{2}{ }_{\mathrm{x}, \mathrm{y}}$ factors of the laser mode were below 1.3.

\subsection{In-band pumping}

The CW laser experiments were extended to in-band pumping (to the ${ }^{3} \mathrm{~F}_{4}$ state, $\lambda_{\mathrm{P}}=1679 \mathrm{~nm}$ ). The input-output characteristics are shown in Fig. 12(a). The maximum output power reached $1.37 \mathrm{~W}$ at $1915-1923 \mathrm{~nm}$ with a slope efficiency $\eta$ of $82.7 \%$ ( $v s$. the absorbed pump power) and the laser threshold was as low as $P_{\mathrm{abs}}=17 \mathrm{~mW}$. The optical-to-optical efficiency $\eta_{\mathrm{opt}}$ was $74.8 \%$ ( $v s$. the incident pump power). For lower output coupling, the slope efficiency gradually decreased. Contrary to the case of conventional pumping, for $T_{\mathrm{OC}}>$ $20 \%$, the laser performance slightly deteriorated. This is attributed to the effect of ETU, see Fig. 1(a). For all OCs, the laser emission was linearly polarized ( $\boldsymbol{E} \| N_{\mathrm{m}}$ ). Neither damage of the WG nor thermal roll-over in the output dependencies were observed.

Typical laser emission spectra for the in-band pumped Tm WG laser are shown in Fig. 12(b). They differ from those recorded with conventional pumping, Fig. 9(b). For low $T_{\mathrm{OC}}<10 \%$, the emission was within two spectral bands centered at $\sim 1.92$ and $1.95 \mu \mathrm{m}$, e.g., at $1908-1921 \mathrm{~nm}$ and $1940-1948 \mathrm{~nm}$ for $T_{\mathrm{OC}}=1.6 \%$. For higher output coupling, only the short-wavelength emission band was observed. For the maximum $T_{\mathrm{OC}}=50 \%$, the laser emission was within three spectral bands centered at $\sim 1.85,1.92$ and $1.95 \mu \mathrm{m}$. These spectral features agree well with the gain spectra of $\mathrm{Tm}^{3+}: \mathrm{KLuW}[12]$.

For the in-band pumping, the pump and laser mode profiles were similar. The laser mode at the output WG facet is presented in Fig. 13(a). It is more symmetric compared to the case of conventional pumping, Fig. 11(b), and more confined within the cladding. The 1D intensity profiles are well fitted with a Gaussian distribution $\left(\mathrm{R}^{2}>0.99\right)$, yielding mode diameters $2 w_{\mathrm{L}}$ of $31.6 \pm 2 \mu \mathrm{m}$ and $36.3 \pm 2$ $\mu \mathrm{m}$ along the horizontal and vertical directions, respectively. These values are lower compared to the case of conventional pumping, indicating weaker interaction with the cladding and, potentially, lower propagation losses (see Section 3.3). The $\mathrm{M}_{\mathrm{x}, \mathrm{y}}^{2}$ factors of the laser mode were as low as 1.1 .

\section{Discussion}

Let us consider the slope efficiency of the Tm WG lasers. First, we estimate the WG propagation losses for both pumping schemes using the Caird analysis [96] modified for the case of high output coupling [30]:

$$
1 / \eta=\left(1 / \eta_{0}\right)\left(1+2 \gamma / \gamma_{\text {OC }}\right)
$$

where $\gamma=-\ln (1-L), L$ is the internal loss per pass, $\gamma_{\mathrm{OC}}=-\ln \left(1-T_{\mathrm{OC}}\right)$, and $\eta_{0}$ is the intrinsic slope efficiency. The plots of the inverse of the slope efficiency, $1 / \eta$, vs. inverse of the output-coupling loss, $1 / \gamma_{\mathrm{OC}}$, are shown in Fig. 14 . Their linear fits yield the $\eta_{0}$ and $L$ parameters. For the Caird analysis to be meaningful, the laser wavelength (more precisely, the Stokes efficiency $\lambda_{\mathrm{P}} / \lambda_{\mathrm{L}}$ ) should be constant for all OCs [96]. In our case, the blue-shift of $\lambda_{\mathrm{L}}$ with increasing output coupling is minor with respect to $\lambda_{\mathrm{P}}$.

For the conventional pumping (considering the data for $T_{\mathrm{OC}} \leq 50 \%$ ), $\eta_{0}=74.2 \pm 7 \%$ and the WG propagation losses $\delta_{\text {loss }}=4.34 \mathrm{~L} / \mathrm{t}$ $=1.3 \pm 0.3 \mathrm{~dB} / \mathrm{cm}$, in agreement with [60]. For the in-band pumping, $\eta_{0}=85.5 \pm 7 \%$ and $\delta_{\text {loss }}=0.2 \pm 0.3 \mathrm{~dB} / \mathrm{cm}$. Both $\delta_{\text {loss }}$ values are specified at the laser wavelength of $\sim 1.9 \mu \mathrm{m}$. The much lower propagation losses in the latter case are attributed to (i) weaker overlap of the pump and laser modes with the WG cladding, Fig. 13(a), and (ii) lower fractional heat loading under in-band pumping leading to
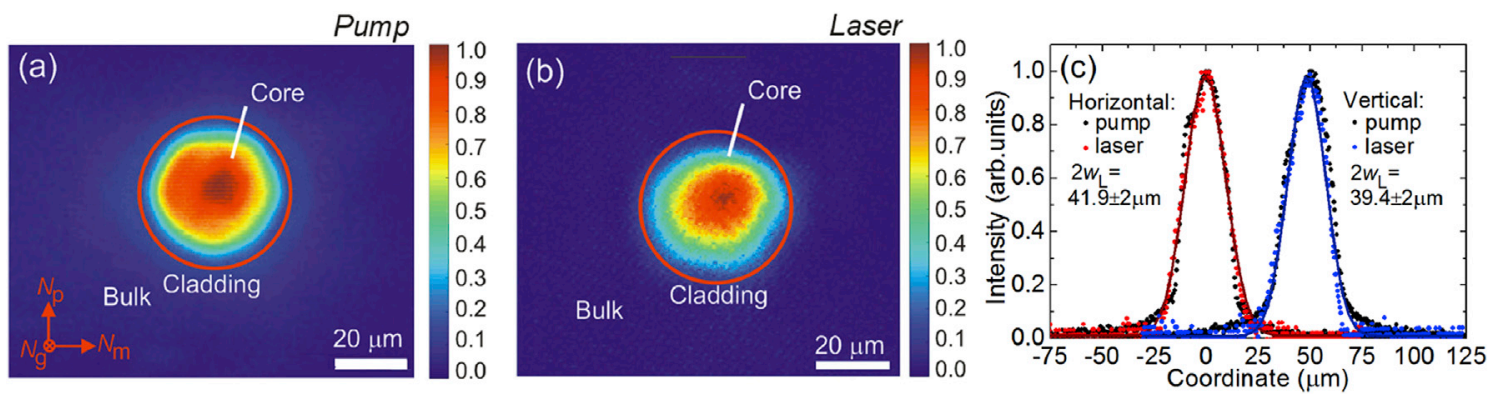

Fig. 11. Mode analysis of the Tm channel WG laser (conventional pumping): (a,b) 2D intensity profiles of the (a) pump mode at $802 \mathrm{~nm}$ and (b) laser mode at $\sim 1840 \mathrm{~nm}$, red circle - position of the WG cladding; (c) 1D intensity plots along the horizontal ( $\| N_{\mathrm{m}}$ ) and vertical (\| $N_{\mathrm{p}}$ ) directions, symbols - experimental data, curves - Gaussian fits. The laser polarization is horizontal. $T_{\mathrm{OC}}=50 \%, P_{\mathrm{abs}}=1.0 \mathrm{~W}$. 

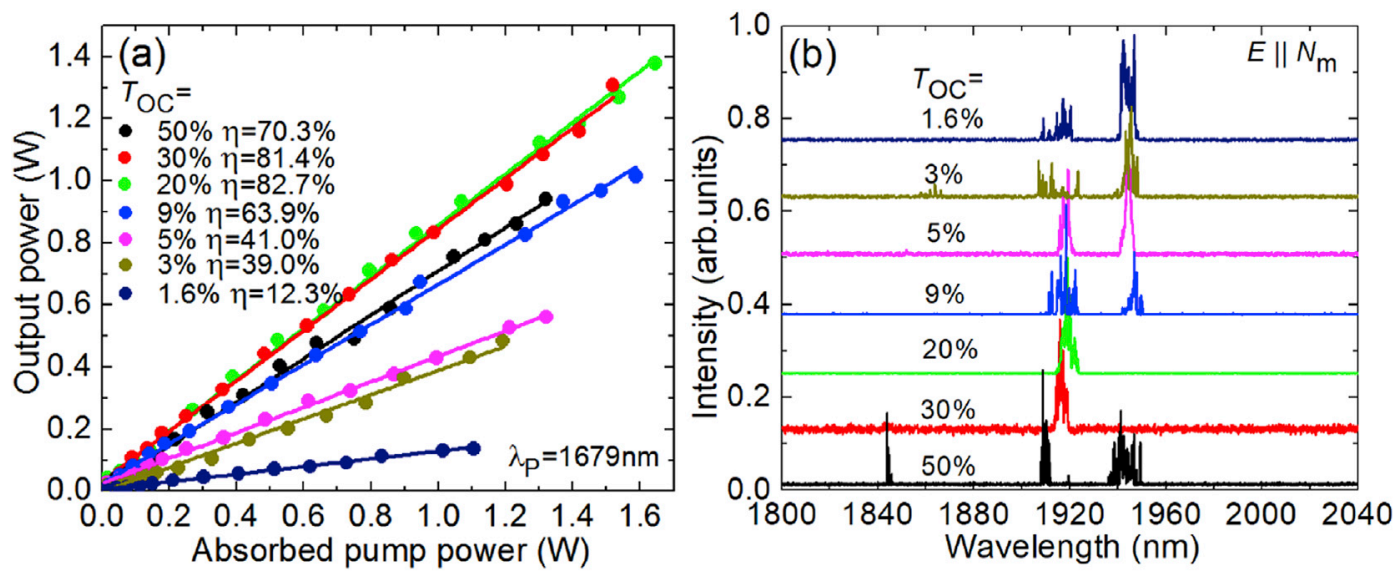

Fig. 12. Continuous-wave Tm channel WG laser with in-band pumping $\left(\lambda_{\mathrm{P}}=1679 \mathrm{~nm}\right)$ : (a) input-output dependencies, $\eta$ - slope efficiency; (b) typical laser emission spectra, $P_{\mathrm{abs}}=1 \mathrm{~W}$. The laser polarization is $\boldsymbol{E} \| N_{\mathrm{m}}$.

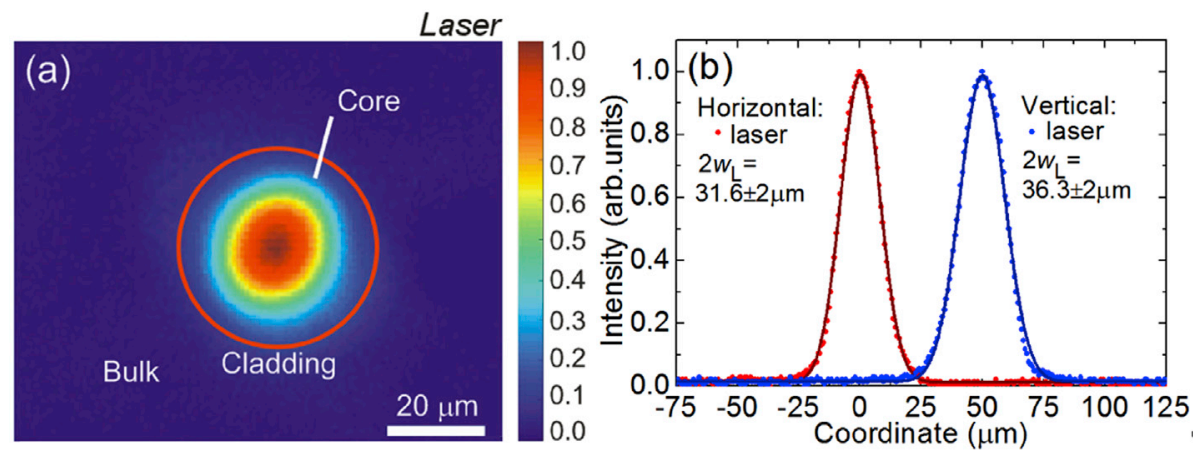

Fig. 13. Mode analysis of the thulium channel waveguide laser (in-band pumping): (a) 2D intensity profile of the laser mode at $\sim 1950 \mathrm{~nm}$, red circle - position of the WG cladding; (b) 1D intensity plots along the horizontal ( $\| N_{\mathrm{m}}$ ) and vertical ( $\| N_{\mathrm{p}}$ ) directions, symbols - experimental data, curves Gaussian fits. The laser polarization is horizontal. $T_{\mathrm{OC}}=50 \%, P_{\mathrm{abs}}=0.9 \mathrm{~W}$.

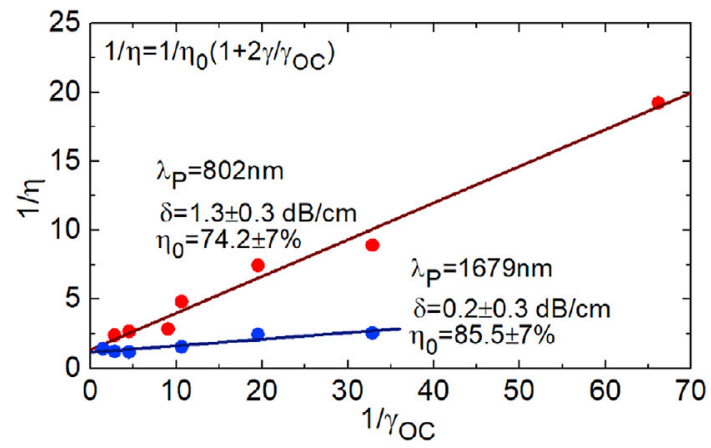

Fig. 14. Caird analysis of the intracavity losses for Tm channel WG lasers with conventional (in red) and in-band pumping (in blue): the plots show the inverse of the slope efficiency, $1 / \eta$, vs. the inverse of the output-coupling losses, $1 / \gamma_{\mathrm{OC}}$, circles - experimental data, line - their fit.

weaker heat dissipation in the WG and, consequently, weaker thermo-optic effects such as stress-induced depolarization losses or diffraction losses caused by the thermal lens. The effect of lower $\delta_{\text {loss }}$ is visible in the emission spectra, as longer wavelengths are generated in the in-band pumped laser, Fig. 12(b), indicating smaller inversion ratios $\beta$.

The upper limit for the slope efficiency $\eta$ of a quasi-three-level solid-state laser is [9]:

$$
\eta \leq \eta_{\text {mode }} \cdot \eta_{\mathrm{OC}} \cdot \eta_{\mathrm{q}} \cdot \eta_{\mathrm{St}, \mathrm{L}}
$$


where $\eta_{\text {mode }}$ is the mode overlap efficiency; $\left.\eta_{\mathrm{OC}}=\ln \left[1-T_{\mathrm{OC}}\right] / \ln \left[1-T_{\mathrm{OC}}\right) \cdot(1-2 L)\right]$ is the outcoupling efficiency (2L is the roundtrip passive loss); $\eta_{\mathrm{q}}$ is the pump quantum efficiency; $\eta_{\mathrm{St}, \mathrm{L}}=\lambda_{\mathrm{P}} / \lambda_{\mathrm{L}}$ is the Stokes efficiency under lasing conditions. For this analysis, we assume an outcoupling corresponding to the best laser performance and use the WG propagation losses values determined above.

Let us first consider conventional pumping $\left(\lambda_{\mathrm{P}}=802 \mathrm{~nm}\right)$. From the measured pump and laser modes, Fig. 11(c), we calculate $\eta_{\text {mode }}$ $=93 \pm 5 \%$. From the determined $\delta_{\text {loss }}$ value, we derive $\eta_{\mathrm{OC}}=88.1 \%$. The pump quantum efficiency in this case is determined mostly by the CR which depends on the Tm doping concentration: for the given $N_{\mathrm{Tm}}, \eta_{\mathrm{q}}=1.75$ [97]. Finally, $\eta_{\mathrm{St}, \mathrm{L}}$ is $4.36 \%$, so that $\eta \leq 62.5 \%$ which agrees well with our results. More details about the pump quantum efficiency for $\mathrm{Tm}^{3+}$ ions can be found elsewhere [98].

For the case of in-band pumping $\left(\lambda_{\mathrm{P}}=1679 \mathrm{~nm}\right)$, a similar analysis is performed yielding the following values: $\eta_{\text {mode }}>99 \%, \eta_{\mathrm{OC}}=$ $94.5 \%, \eta_{\mathrm{q}} \approx 1$ (assuming weak ETU) and $\eta_{\mathrm{St}, \mathrm{L}}=87.4 \%$. As a result, $\eta$ is $\leq 82.6 \%$, again in agreement with our observations. Thus, the higher slope efficiency for the in-band pumped Tm WG laser is due to (i) better overlap between the pump and laser modal profiles, (ii) lower associated intracavity losses and (iii) much higher Stokes efficiency, well exceeding that for the conventional pumping even under efficient CR process. Further discussion about the in-band pumping can be found in a recent study [99].

The upper limit of the slope efficiency for conventional pumping is set by $\eta_{\mathrm{q}}$ determined by CR, and, consequently, by the Tm doping level (3 at.\%). Higher $\eta_{\mathrm{q}}$ approaching its limit (2) is expected in highly-doped ( $\geq 8$ at.\% Tm) samples. However, in our fs-DLW experiments using highly doped crystals the obtained quality of the WGs was low. This low quality is most probably due to the overlap of the writing central wavelength $(795 \mathrm{~nm})$ with the $\mathrm{Tm}^{3+}$ absorption $\left({ }^{3} \mathrm{H}_{6} \rightarrow{ }^{3} \mathrm{H}_{4}\right)$ inducing serious damage to the crystal. This limitation is however absent under in-band pumping where low-doped crystals can be used still leading to a high laser slope efficiency.

The threshold of an in-band pumped quasi-three-level laser can be calculated as [100]:

$$
P_{\mathrm{th}}=\frac{h \nu_{\mathrm{P}}}{\tau_{\mathrm{Tm}}} \frac{k_{\Sigma}+\sigma_{\mathrm{abs}}^{\mathrm{L}} N_{\mathrm{Tm}}}{\sigma_{\mathrm{abs}}^{\mathrm{L}}+\sigma_{\mathrm{SE}}^{\mathrm{L}}} t \frac{\pi w_{\mathrm{P}}^{2}}{2} .
$$

Here, $h$ is the Planck constant, $\nu_{\mathrm{P}}$ is the pump frequency, $k_{\Sigma}$ is the total loss coefficient, $k_{\Sigma}=k_{\mathrm{OC}}+k_{\text {loss }}$, where $k_{\mathrm{OC}}=-\ln \left(1-T_{\mathrm{OC}}\right) / 2 t$ and $k_{\text {loss }}=-\ln (1-2 L) / 2 t$ represent the outcoupling and passive losses, respectively, $\sigma_{\text {abs }}^{\mathrm{L}}=0.17 \times 10^{-20} \mathrm{~cm}^{2}$ and $\sigma_{\text {SE }}^{\mathrm{L}}=1.36 \times 10^{-20} \mathrm{~cm}^{2}$ are the absorption and stimulated-emission cross-sections of $\mathrm{Tm}^{3+}: \mathrm{KLuW}$ at the laser wavelength $\lambda_{\mathrm{L}} \approx 1.92 \mu \mathrm{m}[12]$, respectively, the term $\sigma_{\text {abs }}^{\mathrm{L}} N_{\mathrm{Tm}}$ stands for the reabsorption losses and $\tau_{\mathrm{Tm}}=0.275 \mathrm{~ms}$ [12] is the upper laser level $\left({ }^{3} \mathrm{H}_{4}\right)$ lifetime. Finally, Eq. (3) yields $P_{\text {th }}$ $=19 \mathrm{~mW}$, in good agreement with our experimental result.

For the designed lasers, the confocal parameter of the pump beams is comparable with the crystal thickness: $2 z_{\mathrm{R}}$ was about a few mm (in the crystal) for the conventional and in-band pumping. Thus, one may argue about a bulk (non-waveguiding) regime of laser
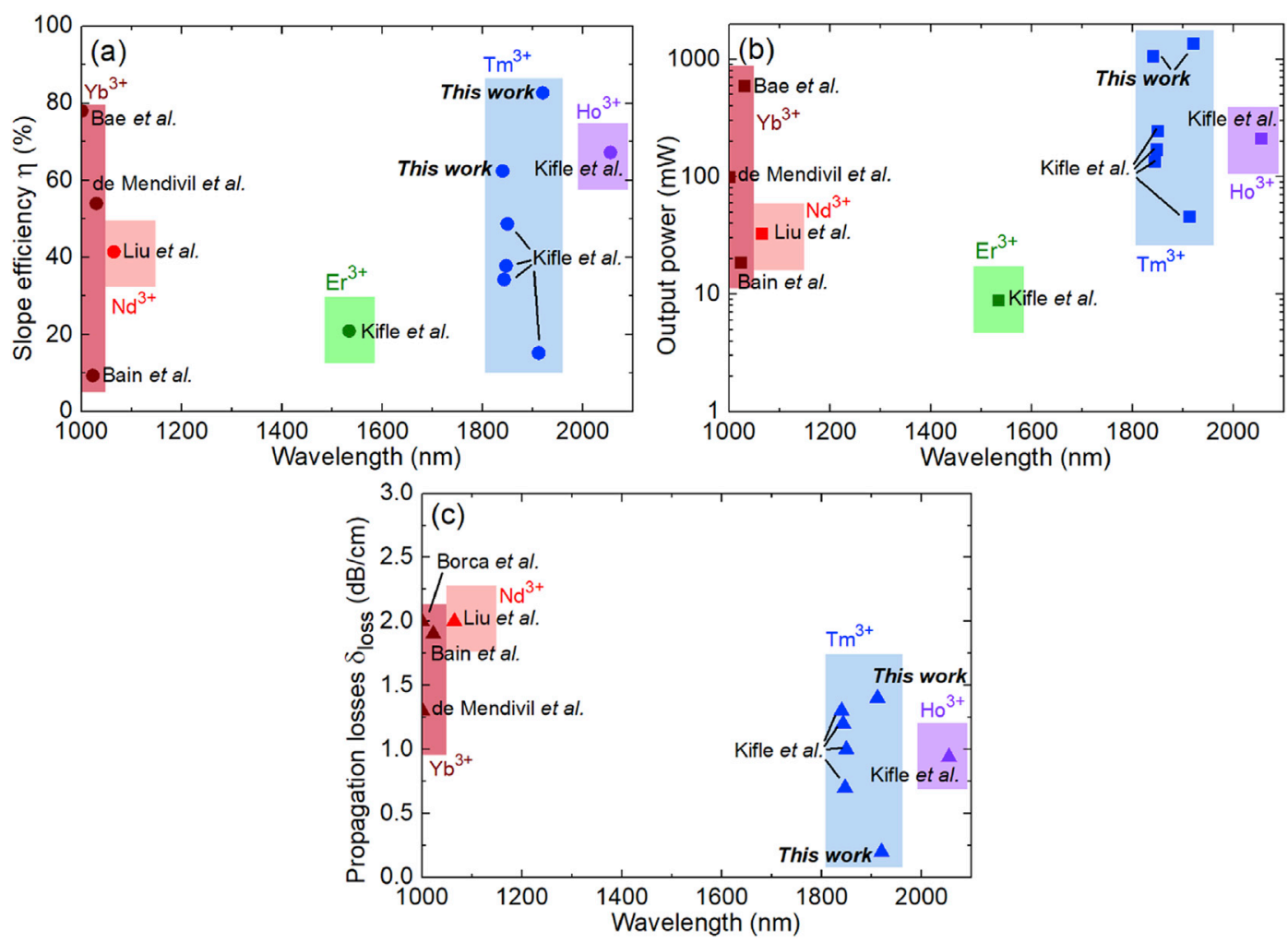

Fig. 15. Summary of the output performance of continuous-wave waveguide lasers produced in rare-earth-doped monoclinic double tungstate (MDT) crystals by fs direct laser writing: (a) slope efficiency $\eta$ vs. the absorbed pump power; (b) output power; (c) propagation losses $\delta_{\text {loss }}$. 
operation. It is known that the thermal lens in $N_{\mathrm{g}}$-cut Tm:KLuW crystal is positive [34] and it supports lasing in a plano-plano cavity. However, when the position of the pump beam was moved out of the WG into the bulk crystal, no laser emission was observed. Moreover, the size of the laser mode was clearly determined by the WG cladding (the estimated radius of the laser mode defined solely by the thermal lens is $\sim 60 \mu \mathrm{m}$ ). Finally, no lasing in the bulk regime is expected without the OC.

\subsection{Fs-DLW double tungstate waveguide lasers}

Let us discuss the previous results on fs-DLW of optical waveguides in MDT crystals. The Tm:KLuW crystal is a representative of this crystal family.

The laser-active WGs were based on MDT crystals doped with $\mathrm{Yb}^{3+}$ and $\mathrm{Nd}^{3+}$ (at $\sim 1 \mu \mathrm{m}$ ), $\mathrm{Er}^{3+}$ (at $\sim 1.5 \mu \mathrm{m}$ ) and $\mathrm{Tm}^{3+}$ and $\mathrm{Ho}^{3+}$ ions (at $\sim 2 \mu \mathrm{m}$ ). A summary of the laser performances (output power and slope efficiency) of the fs-DLW MDT WG lasers is shown in Fig. 15.

As for passive (undoped) crystals, Eaton et al. observed Raman gain around the fs laser inscribed damage tracks in KGdW [101].

Ytterbium WGs. Bain et al. reported on type II buried channel WGs (with a double-track geometry) fabricated in 5 at.\% Yb:KGdW and Yb:KYW crystals [102]. The WG propagation losses were in the range 1.9-3.9 dB/cm. The Yb:KGdW WG laser-generated an output power of $18.6 \mathrm{~mW}$ at $1023 \mathrm{~nm}$ with $\eta=9.3 \%$ ( $v s$. the absorbed pump power). The pump source was a single-mode fiber-coupled $980 \mathrm{~nm}$ InGaAs laser diode. Later, the same authors reported on micro-Raman spectroscopy of such waveguides by monitoring several characteristic Raman bands [103]. The authors concluded that the densification of the double-oxygen WOOW bridges in the lattice is responsible for the refractive index change around the irradiated regions. Borca et al. reported on passive waveguiding in type I and type II buried channel WGs in 2 at.\% Yb:KYW; an estimation of $\delta_{\text {loss }}=2-2.5 \mathrm{~dB} / \mathrm{cm}$ at $\sim 1 \mu \mathrm{m}$ was provided [104]. de Mendívil et al. implemented fs laser writing for material removal of LPE-grown "mixed" $\mathrm{Yb}^{3+}$-doped MDT films [105,106]. The WG propagation losses and the laser performance were governed mostly by the LPE method. The maximum output power was $100 \mathrm{~mW}$ at $1001 \mathrm{~nm}$ with a very high $\eta=78 \%$ [105]. Bae et al. reported on type III surface channel WGs (with a half-ring cladding) in 5 at.\% Yb:KLuW crystals yielding much higher output power of $600 \mathrm{~mW}$ at $\sim 1030 \mu \mathrm{m}$ with $\eta=54 \%$ [107].

Neodymium WGs. Liu et al. reported on type II buried channel WGs in 1 at.\% Nd:KGdW crystal. Passive waveguiding at $633 \mathrm{~nm}$ and propagation losses down to $0.2 \mathrm{~dB} / \mathrm{cm}$ were observed [108]. The same group of authors confirmed the preservation of micro-Raman and micro-luminescence response of the WG core region in similar structures in Nd:KGdW [109]. Liu et al. also reported laser operation in such WGs under Ti:Sapphire laser pumping at $808 \mathrm{~nm}$. The Nd WG laser-generated $33 \mathrm{~mW}$ at $1065 \mathrm{~nm}$ with $\eta=41.4 \%$ and the WG propagation losses were as high as $2 \mathrm{~dB} / \mathrm{cm}$ (at the laser wavelength) [110]. The estimated refractive index change (decrease) due to fs-DLW was $-2.9 \times 10^{-3}$ at the wavelength of $\sim 1 \mu \mathrm{m}$ (in the damage tracks), as determined from the measured numerical aperture of the waveguide [110].

Erbium WGs. The only report on $\sim 1.5 \mu \mathrm{m}$ MDT waveguide laser was based on fs-DLW type III buried channel WG in 1 at.\% Er:KLuW. The WG laser diode-pumped at $981 \mathrm{~nm}$ generated $8.9 \mathrm{~mW}$ at $1533.6 \mathrm{~nm}$ with a slope efficiency of 20.9\% [111]. The laser output was linearly polarized $\left(\boldsymbol{E} \| N_{\mathrm{m}}\right)$.

Thulium WGs. In the first work on $\sim 2 \mu \mathrm{m}$ fs-DLW MDT waveguides, Kifle et al. reported on type III buried channel WGs in 3 at.\% Tm:KLuW with a circular and hexagonal cladding [60]. Under Ti:Sapphire laser pumping at $802 \mathrm{~nm}$, the WG with a circular cladding generated output power of $46 \mathrm{~mW}$ at $1912 \mathrm{~nm}$ corresponding to a slope efficiency of $15.2 \%$. The same authors studied the WGs with a hexagonal (optical lattice-like) cladding in more detail in Ref. [32], including the emission properties at $\sim 2 \mu \mathrm{m}$, micro-Raman spectroscopy and improved laser behavior. An estimation of the refractive index change of $-0.6 \times 10^{-3}$ and the propagation losses of $1.2 \pm$ $0.3 \mathrm{~dB} / \mathrm{cm}$ at the wavelength of $\sim 1.84 \mu \mathrm{m}$ were provided. Furthermore, the power scaling of Tm WG laser with a circular cladding was also demonstrated [112], yielding $247 \mathrm{~mW}$ at $1849.6 \mathrm{~nm}$ with a slope efficiency of $48.7 \%$. The Tm WG lasers operated at the fundamental transverse mode. In Ref. [31], type III surface channel WG geometry (with a half-ring cladding) was implemented for Tm:KLuW. Finite element method simulations of the surface WG accounting for various processes contributing to the refractive index change
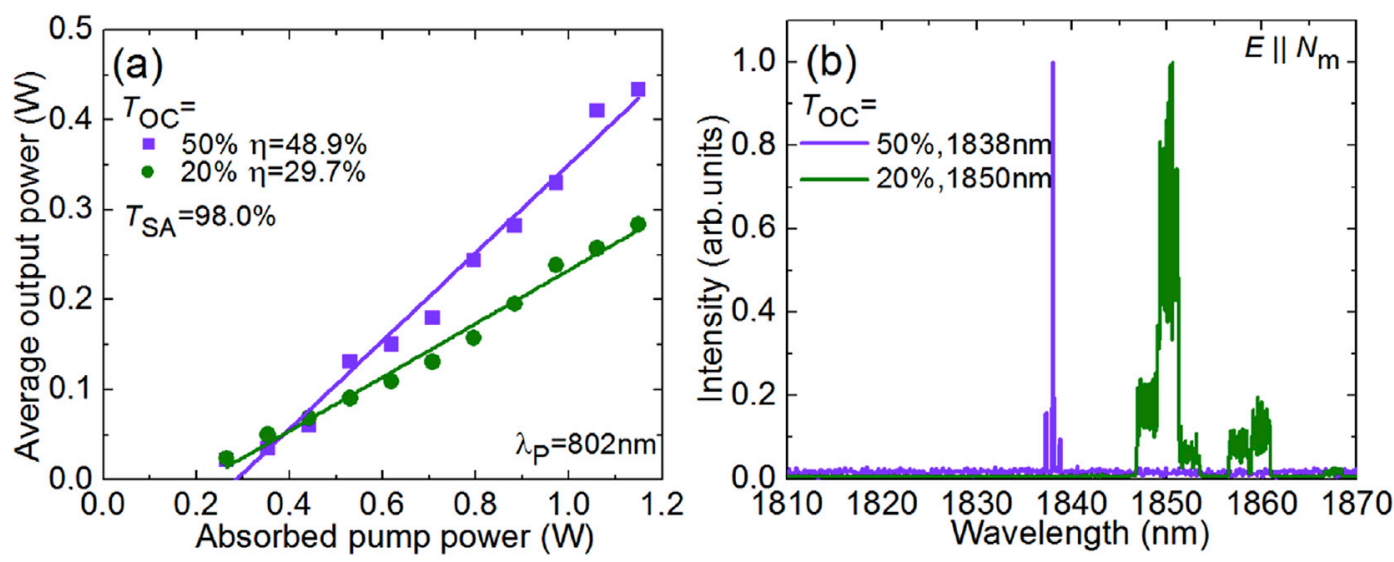

Fig. 16. Passively Q-switched Tm channel WG laser (conventional pumping at $802 \mathrm{~nm}$ ): (a) input-output dependencies, $\eta$ - slope efficiency; (b) typical laser emission spectra measured at the maximum $P_{\mathrm{abs}}$. The laser polarization is $\boldsymbol{E} \| N_{\mathrm{m}} . \mathrm{SA}: \mathrm{Cr}^{2+}: \mathrm{ZnSe}$ with $T_{\mathrm{SA}}=98.0 \%$. 
(damage and stress-optic index changes) have been performed. The refractive index change at sub- $\mu \mathrm{m}$ tracks was estimated from this analysis to be $\Delta n=-0.01+0.0017 i$ at the wavelength of $\sim 1.85 \mu \mathrm{m}$ [31]. Note that the estimated real part of the complex refractive index, $\operatorname{Re}(\Delta n)$, is higher than the value obtained from the measured numerical aperture of a similar waveguide [32].

Holmium WGs. The only report on fs-DLW Ho:MDT WGs was based on buried channel type III WGs fabricated in 5 at.\% Ho:KGdW [113]. The Ho WG laser was in-band pumped by a bulk Tm laser at $1960 \mathrm{~nm}$ and it generated $212 \mathrm{~mW}$ at $2055 \mathrm{~nm}$ with a slope efficiency of $67.2 \%$. The WG propagation losses were $0.94 \pm 0.2 \mathrm{~dB} / \mathrm{cm}$ (at the laser wavelength). Micro-Raman and micro-luminescence mapping of the WG end-facet were also reported. In both Tm and Ho fs-DLW WG lasers, the output was linearly polarized $\left(\boldsymbol{E} \| N_{\mathrm{m}}\right)[112,113]$. For Ho WG, it was spatially multimode [113].

\section{Passively Q-switched lasers}

\subsection{Laser performance}

Passive Q-switching was performed using conventional pumping at $802 \mathrm{~nm}$ exclusively, as already mentioned, because of the SA absorption at the in-band pumped wavelength around $1680 \mathrm{~nm}$. We started with the $\mathrm{Cr}^{2+}: \mathrm{ZnSe}$ SA having the smallest modulation depth $\left(T_{\mathrm{SA}}=98.0 \%\right)$ and, thus, the lowest insertion losses. The pump power was limited to $P_{\mathrm{abs}} \approx 1.15 \mathrm{~W}$ since above this level the pulse stability degraded due to significant heating of the SA by the non-absorbed pump power. The input-output dependencies of the passively Q-switched (PQS) Tm WG laser are shown in Fig. 16(a). The maximum average output power was $434 \mathrm{~mW}$ at $1838 \mathrm{~nm}$ with a slope efficiency $\eta=48.9 \%$ (for $T_{\mathrm{OC}}=50 \%$ ). The laser threshold was at $P_{\mathrm{abs}}=265 \mathrm{~mW}$. Considering the output power achieved in the CW mode (at the same pump level), the Q-switching conversion efficiency $\eta_{\text {conv }}$ was $67.9 \%$. For lower outcoupling $\left(T_{\mathrm{OC}}=20 \%\right)$, the laser generated only $284 \mathrm{~mW}$ at $\sim 1850 \mathrm{~nm}$ with $\eta=29.7 \%$ and higher $\eta_{\text {conv }}=80.2 \%$.

Typical laser emission spectra are shown in Fig. 16(b). For higher outcoupling, the spectrum is narrower due to stronger competition of laser lines saturating the SA. The relatively high Q-switching conversion efficiencies and the minor change of the laser wavelength with respect to the CW regime are evidence for relatively low insertion loss of the SA. For both OCs, the laser emission was linearly polarized $\left(\boldsymbol{E} \| N_{\mathrm{m}}\right)$.

The pulse duration (defined as FWHM) $\Delta \tau_{\mathrm{p}}$ and the pulse repetition frequency (PRF) were determined directly and the pulse energy was calculated, $E_{\text {out }}=P_{\text {out }} / \mathrm{PRF}$ ( $P_{\text {out }}-$ average output power). The dependence of these pulse characteristics on the pump power is illustrated in Fig. 17 (for the $\mathrm{Cr}^{2+}: \mathrm{ZnSe}$ SA with $T_{\mathrm{SA}}=98.0 \%$ ). Better pulse characteristics were observed for higher outcoupling: the pulse duration/energy reached $8.2 \mathrm{~ns} / 7.0 \mu \mathrm{J}$ at the maximum pump power for $T_{\mathrm{OC}}=50 \%$. The $\Delta \tau_{\mathrm{p}}$ and $E_{\text {out }}$ values showed only a weak dependence on the pump level contrary to the PRF which increased almost linearly, from 5 to $62 \mathrm{kHz}$. As a result, the peak power $P_{\text {peak }}=$ $E_{\text {out }} / \Delta \tau_{\mathrm{p}}$ reached $0.85 \mathrm{~kW}$.

The oscilloscope traces of the shortest Q-switched pulses achieved with both studied OCs are shown in Fig. 18(a). The pulses have a nearly Gaussian temporal shape. Typical pulse trains of the PQS Tm WG laser corresponding to a PRF of 9.3 and $31 \mathrm{kHz}$ are shown in Fig. 18(b) and (c). The latter confirms the excellent stability of the PQS operation with a measured pulse-to-pulse r.m.s. timing jitter of $<5 \%$ and intensity instabilities in the pulse train of $<10 \%$.

The mode profile of the PQS laser was similar to that of the CW one, cf. Fig. 11(b).

\subsection{Effect of the saturable absorber modulation depth}

To investigate the effect of the modulation depth, we compared $\mathrm{Cr}^{2+}: \mathrm{ZnS}$ and $\mathrm{Cr}^{2+}: \mathrm{ZnSe}$ SAs with different small-signal transmission $T_{\mathrm{SA}}$. The PQS laser performance was studied at a reference pump power of $P_{\mathrm{abs}}=0.80 \mathrm{~W}$ (well above the laser threshold whilst below the range of instabilities caused by the residual pump) using the high-transmission output coupler, $T_{\mathrm{OC}}=50 \%$.

The laser characteristics for the studied SAs are summarized in Table 2. With the decrease of the small-signal SA transmission from $98.0 \%$ to $64.3 \%$, the average output power gradually decreased from 244 to $55 \mathrm{~mW}$ (thus, the Q-switching conversion efficiency dropped from $61.7 \%$ to $13.9 \%$ ) because SAs with smaller transmission introduced higher insertion losses. The laser wavelength for all SAs was at $\sim 1838 \mathrm{~nm}$. Because of the high inversion ratios $\beta$, the gain spectrum of $\mathrm{Tm}^{3+}: \mathrm{KLuW}$ features a local maximum at $\sim 1.84 \mu \mathrm{m}$ [12]. Thus, no wavelength blue-shift is expected even for greatly increased intracavity losses.

Regarding the pulse characteristics, the pulse duration notably shortened with decreasing $T_{\mathrm{SA}}$, from 9.3 down to $2.6 \mathrm{~ns}$, Fig. 19 (a), representing a record-short value for any passively Q-switched WG laser at $\sim 2 \mu \mathrm{m}$. This behavior is typical for PQS solid-state lasers. Corresponding oscilloscope traces of the single Q-switched pulses are shown in Fig. 19(c). The pulse energy was, however, weakly dependent on $T_{\mathrm{SA}}$, Fig. 19(b), reaching $6.9 \mu \mathrm{J}$ for the SA with the highest optical density $\left(T_{\mathrm{SA}}=64.3 \%\right)$. The latter may originate from the heating of the SA by the residual pump radiation. As a result, the peak power for this SA was as high as $2.66 \mathrm{~kW}$. The PRF decreased with decreasing $T_{\mathrm{SA}}$, from 41.0 to $8.0 \mathrm{kHz}$ related to the corresponding drop of the average output power.

The oscilloscope traces of the pulse trains for the $\mathrm{Cr}^{2+}: \mathrm{ZnS}$ SAs are shown in Fig. 20 indicating stable PQS operation without any signs of multi-pulse generation. For optically dense $\mathrm{Cr}^{2+}: \mathrm{ZnS}$ SAs, compared to Fig. 18(b) and (c), the intensity instabilities were higher but still below $20 \%$.

\section{Discussion}

According to the relation between the recovery time of initial absorption $\tau_{\text {rec }}$ and the characteristic time of formation of a single Qswitched pulse, $\Delta \tau$, typically in the ns-range, the SAs employed in PQS solid-state lasers are classified as "fast" $\left(\tau_{\text {rec }}\right.$ " $\left.\Delta \tau\right)$ and "slow" $\left(\tau_{\text {rec }}\right.$ 

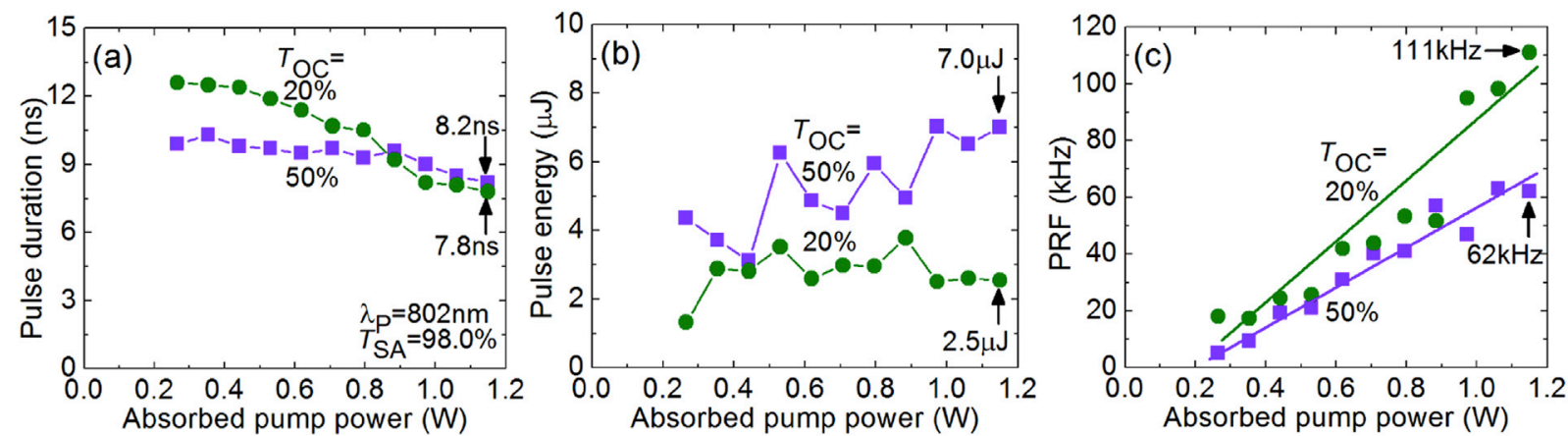

Fig. 17. Characteristics of the passively Q-switched Tm channel WG laser (conventional pumping at $802 \mathrm{~nm}$ ): (a) pulse duration (FWHM), (b) pulse repetition frequency (PRF), (c) pulse energy. SA: $\mathrm{Cr}^{2+}: \mathrm{ZnSe}, T_{\mathrm{SA}}=98.0 \%$.
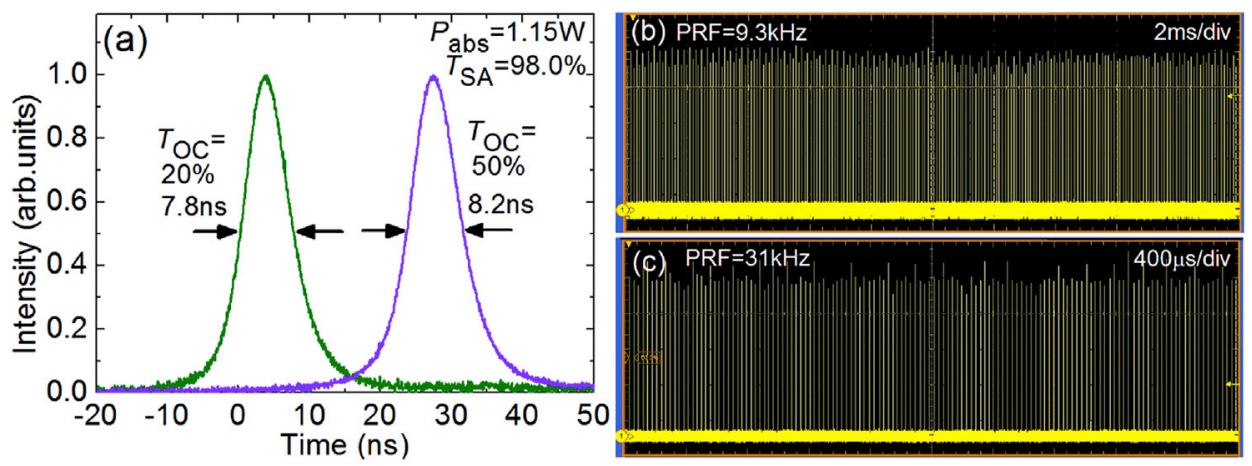

Fig. 18. Oscilloscope traces of (a) the shortest single Q-switched pulses and (b) pulse trains at a PRF of $9.3 \mathrm{kHz}$ and $31 \mathrm{kHz}\left(T_{\mathrm{OC}}=50 \%\right)$ for the passively Q-switched Tm channel WG laser. SA: $\mathrm{Cr}^{2+}: \mathrm{ZnSe}$ with $T_{\mathrm{SA}}=98.0 \%$.

Table 2

Output characteristics* of passively Q-switched thulium channel waveguide lasers**.

\begin{tabular}{|c|c|c|c|c|c|c|c|}
\hline SA & $\begin{array}{l}T_{\mathrm{SA}} \\
\%\end{array}$ & $P_{\text {out }}, \mathrm{mW}$ & $\begin{array}{l}\eta_{\text {conv }} \\
\%\end{array}$ & $\Delta \tau_{\mathrm{p}}, \mathrm{ns}$ & $\begin{array}{l}E_{\text {out }}, \\
\mu \mathrm{J}\end{array}$ & PRF, kHz & $P_{\text {peak }}, \mathrm{kW}$ \\
\hline $\mathrm{Cr}^{2+}: \mathrm{ZnSe}$ & 98.0 & 244 & 61.7 & 9.3 & 6.0 & 41.0 & 0.64 \\
\hline \multirow[t]{4}{*}{$\mathrm{Cr}^{2+}: \mathrm{ZnS}$} & 86.7 & 177 & 44.8 & 5.8 & 5.1 & 34.7 & 0.88 \\
\hline & 75.8 & 113 & 28.6 & 3.7 & 6.0 & 18.8 & 1.63 \\
\hline & 69.2 & 74 & 18.7 & 3.1 & 7.1 & 10.4 & 2.30 \\
\hline & 64.3 & 55 & 13.9 & 2.6 & 6.9 & 8.0 & 2.66 \\
\hline
\end{tabular}

${ }^{*} P_{\text {out }}$ - average output power, $\eta_{\text {conv }}-$ Q-switching conversion efficiency, $\Delta \tau_{\mathrm{p}}-$ pulse duration, $E_{\text {out }}-$ pulse energy, PRF - pulse repetition frequency, $P_{\text {peak }}$ - peak power. Bold numbers correspond to the best results.

$* *$ At a reference $P_{\mathrm{abs}}=0.80 \mathrm{~W}$, for $T_{\mathrm{OC}}=50 \%$.

» $\Delta \tau) . \mathrm{Cr}^{2+}$-doped chalcogenides (ZnS and ZnSe) are classical "slow" SAs for PQS $\sim 2 \mu \mathrm{m}$ lasers. They allow obtaining either high pulse energies (up to $\mathrm{mJ}$ ) [88] or very short pulses (down to sub-ns) [36] while operating at low repetition rates (few $\mathrm{kHz}$ ) because $\tau_{\text {rec }}$ for these materials is about 5-6 $\mu$ s [90] (associated with the lifetime of the ${ }^{5} \mathrm{E}\left({ }^{5} \mathrm{D}\right) \mathrm{Cr}^{2+}$ state).

"Slow" SAs feature a weak dependence of the PQS laser pulse characteristics (energy and duration) on the pump power if the following criterion is satisfied [114]:

$$
X=\frac{\sigma_{\mathrm{GSA}}}{\sigma_{\mathrm{abs}}^{\mathrm{L}}+\sigma_{\mathrm{SE}}^{\mathrm{L}}} \frac{A_{\mathrm{AE}}}{A_{\mathrm{SA}}}>>1
$$

Here, $A_{\mathrm{AE}}$ and $A_{\mathrm{SA}}$ are the laser mode areas in the active element and in the SA, respectively ( $A_{\mathrm{AE}} \approx A_{\mathrm{SA}}$ for the WG lasers). For the $\mathrm{Cr}^{2+}: \mathrm{ZnS}$ and $\mathrm{Cr}^{2+}: \mathrm{ZnSe}$ SAs, at the laser wavelength of $1.84 \mu \mathrm{m}, X$ are 17 and 26 , respectively (here, $\sigma_{\text {abs }}^{\mathrm{L}}=1.38 \times 10^{-20} \mathrm{~cm}^{2}$ and $\sigma^{\mathrm{L}}$ SE $\left.=3.67 \times 10^{-20} \mathrm{~cm}^{2}[12]\right)$. Thus, the proposed laser design is suitable for efficient "slow" SA passive Q-switching.

Now let us determine the intracavity fluence on the SA [115]: 

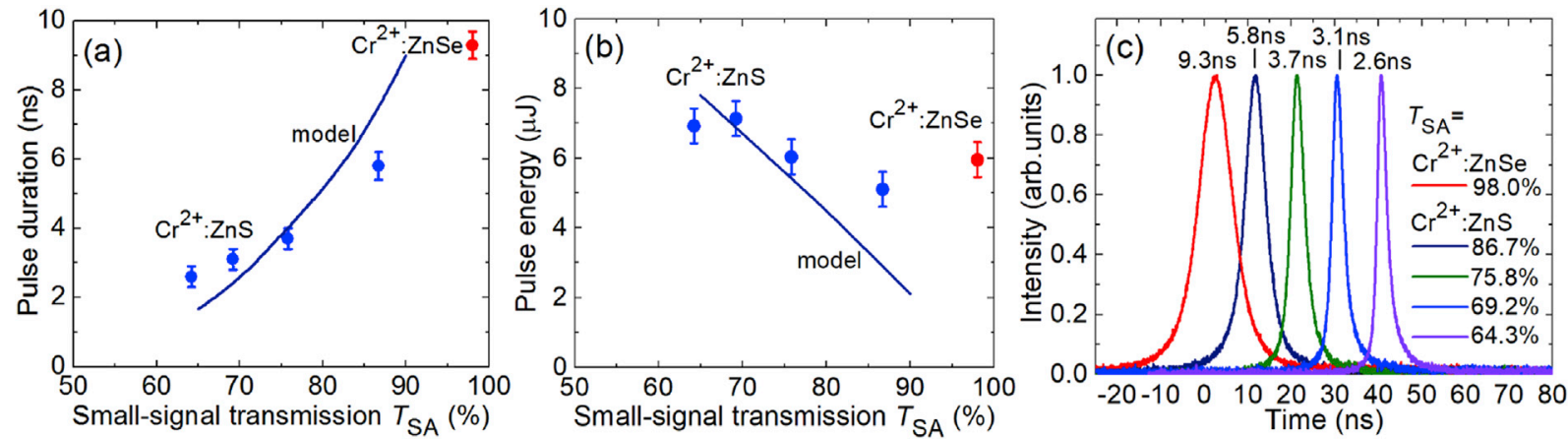

Fig. 19. Tm channel WG laser passively Q-switched by $\mathrm{Cr}^{2+}: \mathrm{ZnS}$ and $\mathrm{Cr}^{2+}: \mathrm{ZnSe}$ SAs with different small-signal transmission $T_{\mathrm{SA}}$ : (a) pulse duration, (b) pulse energy and (c) the corresponding oscilloscope traces. Panels (a),(b): symbols - experimental data, curves - numerical modeling. $T_{\mathrm{OC}}=50 \%$, $P_{\text {abs }}=0.8 \mathrm{~W}$.
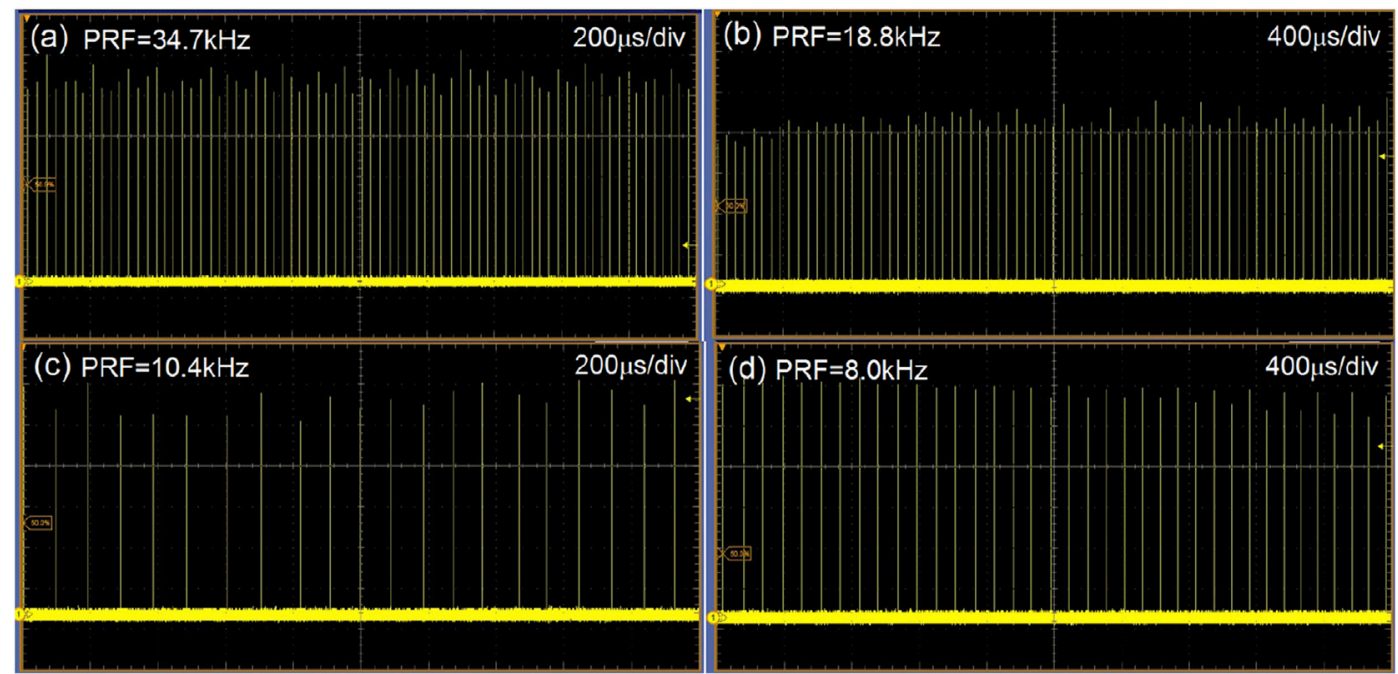

Fig. 20. Oscilloscope traces of the pulse trains from the Tm channel WG lasers passively Q-switched by $\mathrm{Cr}^{2+}: \mathrm{ZnS}$ SAs with different small-signal transmission: $T_{\mathrm{SA}}=$ (a) $86.7 \%$, (b) $75.8 \%$, (c) $69.2 \%$ and (d) $64.3 \%$. $P_{\mathrm{abs}}=0.8 \mathrm{~W}, T_{\mathrm{OC}}=50 \%$.

Table 3

An overview of passively Q-switched thulium waveguide lasers reported so far ${ }^{\mathrm{a}}$.

\begin{tabular}{|c|c|c|c|c|c|c|c|c|}
\hline Gain material & SA & $P_{\text {out }}, \mathrm{mW}$ & $\lambda_{\mathrm{L}}, \mathrm{nm}$ & $\begin{array}{l}\eta \\
\%\end{array}$ & $\Delta \tau_{\mathrm{p}}, \mathrm{ns}$ & $E_{\text {out }}, \mathrm{nJ}$ & PRF, kHz & Ref. \\
\hline \multicolumn{9}{|l|}{ LPE-based } \\
\hline \multirow[t]{4}{*}{ Tm:KYW } & $\mathrm{Cr}^{2+}: \mathrm{ZnS}$ & 1.2 & 1.845 & $\sim 3$ & 1200 & 120 & 10 & [17] \\
\hline & graphene & 6.5 & 1.832 & 9 & 195 & 5.8 & 1130 & [118] \\
\hline & & 26.7 & 1.834 & 11.3 & 98 & 21 & 1270 & [119] \\
\hline & SWCNTs & 45.6 & 1.835 & 22.5 & 83 & 33 & 1390 & [18] \\
\hline \multicolumn{9}{|l|}{ Fs-DLW } \\
\hline \multirow[t]{2}{*}{ Tm:ZBLAN } & graphene & 6 & $\sim 1.9$ & $\sim 5$ & 2760 & 240 & 25 & [120] \\
\hline & $\mathrm{Bi}_{2} \mathrm{Te}_{3}$ & 16.3 & 1.88 & 1.3 & 1400 & 370 & 44.1 & [121] \\
\hline Tm:YAG & graphene & 6.5 & 1.944 & $\sim 2$ & $<500$ & 9.5 & 684 & [122] \\
\hline \multirow[t]{6}{*}{ Tm:KLuW } & SWCNTs & 10.3 & 1.841 & 3.8 & 50 & 7 & 1480 & {$[60]$} \\
\hline & & 150 & 1.847 & 34.6 & 98 & 106 & 1420 & [31] \\
\hline & graphene & 24.9 & 1.845 & 9.3 & 88 & 18 & 1390 & [112] \\
\hline & $\mathrm{MoS}_{2}$ & 22.1 & 1.843 & 8.5 & 73 & 18 & 1580 & [112] \\
\hline & $\mathrm{Cr}^{2+}: \mathrm{ZnSe}$ & 430 & 1.838 & 48.9 & 8.2 & $7.0 \times 10^{3}$ & 61.6 & This work \\
\hline & $\mathrm{Cr}^{2+}: \mathrm{ZnS}$ & 55.4 & 1.833 & - & 2.6 & $6.9 \times 10^{3}$ & 8 & This work \\
\hline
\end{tabular}

${ }^{\text {a }} P_{\text {out }}-$ average output power, $\lambda_{\mathrm{L}}$ - laser wavelength, $\eta$ - slope efficiency, $\Delta \tau_{\mathrm{p}}$ - pulse duration, $E_{\text {out }}-$ pulse energy, PRF - pulse repetition frequency. Bold numbers correspond to the best results. 


$$
F_{\text {in }}=\frac{2-T_{\mathrm{OC}}}{T_{\mathrm{OC}}} \frac{2 E_{\mathrm{out}}}{\pi w_{\mathrm{L}}^{2}} .
$$

Here, $T_{\mathrm{OC}}$ is the transmission of the output coupler, $E_{\text {out }}$ is the output pulse energy, $w_{\mathrm{L}}$ is the radius of the intracavity laser mode and the factor " 2 " indicates a nearly Gaussian laser mode. For the SAs made of $\mathrm{Cr}^{2+}: \mathrm{ZnSe}\left(T_{\mathrm{SA}}=98.0 \%\right)$ and $\mathrm{Cr}^{2+}: \mathrm{ZnS}\left(T_{\mathrm{SA}}=96.7 \%\right)$ yielding the lowest pulse energies, $F_{\text {in }}=2.4 \mathrm{~J} / \mathrm{cm}^{2}$ and $2.9 \mathrm{~J} / \mathrm{cm}^{2}$, respectively. These values have to be compared with the saturation fluence of the SAs, $F_{\mathrm{S}}=\left(h \nu_{\mathrm{L}}\right) / \sigma_{\mathrm{GSA}}$, where $\nu_{\mathrm{L}}$ is the laser frequency. The latter amount to $F_{\mathrm{S}}=0.17 \mathrm{~J} / \mathrm{cm}^{2}$ and $0.11 \mathrm{~J} / \mathrm{cm}^{2}$, respectively. Thus, all SAs are fully bleached.

During the passive Q-switching experiments, no damages of the SAs nor the WG were observed. The latter allows estimating a lower limit of the laser induced damage threshold (LIDT) for $\mathrm{Cr}^{2+}$-doped chalcogenides for ns-pulses at a wavelength of $\sim 2 \mu \mathrm{m}$. Considering the maximum $F_{\text {in }}$ values obtained on our experiments, LIDT $\geq 3.3 \pm 0.5 \mathrm{~J} / \mathrm{cm}^{2}$ for both materials. This value agrees well with a recent report [92].

The pulse characteristics (duration/energy) were calculated using a model of a quasi-three level laser material and a "slow" SA [116, 117]. The results are shown in Fig. 19(a) and (b). Both the predicted trends for the pulse characteristics and their values agree with the experiment.

In Table 3, we summarized the results on passively Q-switched Tm WG lasers reported so far [17,18,31,60,112,118-122]. Two classes of SAs were implemented, namely, "fast" and "slow" ones. The latter group comprises of $\mathrm{Cr}^{2+}$-doped chalcogenides (ZnS, ZnSe) while the former one contains various nanostructures, such as graphene (a single layer of carbon atoms arranged in a honeycomb lattice, a representative 2D material [123,124]), single-walled carbon nanotubes (SWCNTs - rolled sheets of graphene [125]), transition metal dichalcogenides (TMDs, $\mathrm{MoS}_{2}[126,127]$ ) and topological insulators (TIs, $\mathrm{Bi}_{2} \mathrm{Te}_{3}$ [128]). The TMDs and TIs are the graphene-inspired 2D materials containing few weakly interacting atomic layers.

The thulium WG lasers Q-switched by nanostructure-based SAs typically operated at low average output powers (limited by the thermal effects in the SA [129]) and at high repetition rates (hundreds of $\mathrm{kHz}$ - few MHz) determined by their low modulation depth (e.g., $\sim 1.5 \%$ for a single layer of carbon atoms - graphene [130]). As a result, the pulse energy was about tens to hundreds nJ and the pulse durations were in the $\mu$ s range (except of configurations where it was reduced due to the short cavity length and, hence, short roundtrip time). Furthermore, the slope efficiency of such lasers was low indicating the need for further optimization of insertion losses in such nanostructures. However, they still can be considered as a cheap and broadband alternative to Semiconductor Saturable Absorber Mirrors (SESAMs) [131].

The only previous report on $\mathrm{Cr}^{2+}: \mathrm{ZnS}$ Q-switching of a Tm WG laser presented moderate pulse characteristics (pulse duration/energy: $1.2 \mu \mathrm{s} / 120 \mathrm{~nJ}$ ) corresponding to a low average output power of $1.2 \mathrm{~mW}$ with a slope efficiency of about $3 \%$. In the present work, we fully explore the potential of $\mathrm{Cr}^{2+}$-doped chalcogenides as "slow" SAs by reaching simultaneously high pulse energies (for WG lasers, namely few $\mu \mathrm{J}$ ), short pulse durations (few ns) and, thus, record-high peak powers. Furthermore, the good thermal properties of ZnS and ZnSe allowed for power scaling reaching record-high average output powers for this type of lasers. Note that this operation regime corresponded to low repetition rates (few tens $\mathrm{kHz}$ ).

\section{Conclusion}

To conclude, femtosecond Direct Laser Writing is a powerful method to fabricate single-mode active (Tm ${ }^{3+}$-doped) channel waveguides. We have extended this method to anisotropic crystals for highly efficient and power-scalable laser emission at $\sim 2 \mu \mathrm{m}$. Using two different pump schemes, conventional pumping around $800 \mathrm{~nm}$ relying on cross-relaxation and in-band pumping at $1678 \mathrm{~nm}$, we demonstrated for the first time watt-level continuous-wave output from a Tm channel WG laser produced by fs-DLW. For the latter pump scheme, the output power reached $1.37 \mathrm{~W}$ at $1915-1923 \mathrm{~nm}$ with a record-high slope efficiency of $82.7 \%$ almost approaching the Stokes limit, while the laser threshold was as low as $17 \mathrm{~mW}$. The laser output was spatially single-mode with a naturally-selected linear polarization. The estimated WG propagation losses were relatively low, $0.2 \pm 0.3 \mathrm{~dB} / \mathrm{cm}$ at the wavelength of $\sim 1.9 \mu \mathrm{m}$, and comparable to the LPE-based WGs due to the weak leakage of the pump/laser modes through the WG cladding and reduced thermal effects under inband pumping.

In-band pumping of fs-DLW Tm channel WGs using $\sim 1.7 \mu \mathrm{m}$ Raman fiber lasers (RFLs) represents an efficient strategy for highpower integrated light sources at $\sim 2 \mu \mathrm{m}$. A proper design of the RFL wavelength will help to reach higher pump absorption (which was ensured in the present work by double-pass pumping). Moreover, by applying dielectric coatings to the WG facets, direct fiber-towaveguide light coupling can be implemented.

The combination of fs-DLW single-mode Tm channel WGs and $\mathrm{Cr}^{2+}$-doped chalcogenides (ZnS or ZnSe) acting as "slow" saturable absorbers represents an efficient way to generate few ns-long pulses at kHz-range repetition rates. Such compact and robust PQS WG lasers can be used as seed sources for further amplification. We achieved the shortest pulses (2.6 ns) and the highest peak power (2.66 $\mathrm{kW}$ ) ever extracted from a PQS WG laser at $\sim 2 \mu \mathrm{m}$.

The good power scalability, low internal losses and spatially single-mode output make the developed WGs interesting for modelocked WG lasers operating at high repetition rates (GHz-range) [132-135]. In particular, the studied gain material, Tm:KLu(WO$)_{2}$, is known for its smooth and broad emission spectra at $\sim 2 \mu \mathrm{m}$ utilized in mode-locked bulk lasers [38]. To ensure low mode-locking thresholds, the WG length should be increased up to 1-2 cm which has been already realized in our writing experiments.

Another interesting direction applying Tm channel WG lasers is the extension of their emission wavelength well beyond $2 \mu \mathrm{m}$ (into the shortwave- and midwave-infrared spectral range). One way is the use of vibronic laser emission, as demonstrated in the present work. An alternative is the laser operation on the ${ }^{3} \mathrm{H}_{4} \rightarrow{ }^{3} \mathrm{H}_{5}$ laser transition at $\sim 2.3 \mu \mathrm{m}[136,137]$. 
Funding

Spanish Government, MINECO (MAT2016-75716-C2-1-R (AEI/FEDER,UE), FIS2017-87970-R); Junta de Castilla y León (SA287P18); Generalitat de Catalunya (2017SGR755).

\section{Acknowledgments}

E. K. acknowledges financial support from the Generalitat de Catalunya under grants 2016FI_B00844, 2017FI_B100158, and 2018FI_B200123. This work was supported by French Agence Nationale de la Recherche (ANR) through the LabEx EMC3 project FASTMIR, the European Community funds FEDER and the Normandie region. P.L. thanks Ms. Daria Maliarova for the help with the illustrations.

\section{References}

[1] G.D. Marshall, A. Politi, J.C.F. Matthews, P. Dekker, M. Ams, M.J. Withford, J.L. O'Brien, Laser written waveguide photonic quantum circuits, Optic Express 17 (15) (2009) 12546-12554.

[2] J.I. Mackenzie, Dielectric solid-state planar waveguide lasers: a review, IEEE J. Sel. Top. Quant. Electron. 13 (3) (2007) 626-637.

[3] F. Chen, J.R. Vázquez de Aldana, Optical waveguides in crystalline dielectric materials produced by femtosecond-laser micromachining, Laser Photon. Rev. 8 (2) (2014) 251-275.

[4] K. Scholle, S. Lamrini, P. Koopmann, P. Fuhrberg, $2 \mu \mathrm{m}$ laser sources and their possible applications, in: B. Pal (Ed.), In Frontiers in Guided Wave Optics and Optoelectronics, Intech, 2010, pp. 471-500.

[5] A. Rameix, C. Borel, B. Chambaz, B. Ferrand, D.P. Shepherd, T.J. Warburton, D.C. Hanna, A.C. Tropper, An efficient, diode-pumped, 2 um Tm:YAG waveguide laser, Optic Commun. 142 (4-6) (1997) 239-243.

[6] S. McDaniel, F. Thorburn, A. Lancaster, R. Stites, G. Cook, A. Kar, Operation of Ho:YAG ultrafast laser inscribed waveguide lasers, Appl. Optic. 56 (12) (2017) 3251-3256.

[7] J.R. Macdonald, S.J. Beecher, A. Lancaster, P.A. Berry, K.L. Schepler, A.K. Kar, Ultrabroad mid-infrared tunable Cr:ZnSe channel waveguide laser, IEEE J. Sel. Top. Quant. Electron. 21 (1) (2014) 375-379.

[8] R.C. Stoneman, L. Esterowitz, Efficient, broadly tunable, laser-pumped Tm:YAG and Tm:YSGG cw lasers, Opt. Lett. 15 (9) (1990) $486-488$.

[9] K. van Dalfsen, S. Aravazhi, C. Grivas, S.M. García-Blanco, M. Pollnau, Thulium channel waveguide laser with 1.6 W of output power and $\sim 80 \%$ slope efficiency, Opt. Lett. 39 (15) (2014) 4380-4383.

[10] W. Bolanos, F. Starecki, A. Benayad, G. Brasse, V. Ménard, J.-L. Doualan, A. Braud, R. Moncorgé, P. Camy, Tm:LiYF 4 planar waveguide laser at 1.9 ^m, Opt. Lett. 37 (19) (2012) 4032-4034.

[11] Ò. Silvestre, M.C.M. Rico, F. Güell, M. Aguiló, F. Díaz, Thulium doped monoclinic KLu(WO 4$)_{2}$ single crystals: growth and spectroscopy, Appl. Phys. B 87 (4) (2007) 707-716.

[12] V. Petrov, M.C. Pujol, X. Mateos, Ò. Silvestre, S. Rivier, M. Aguiló, R.M. Solé, J.H. Liu, U. Griebner, F. Díaz, Growth and properties of KLu(WO 4$)_{2}$, and novel ytterbium and thulium lasers based on this monoclinic crystalline host, Laser Photon. Rev. 1 (2) (2007) 179-212.

[13] O. Antipov, A. Novikov, S. Larin, I. Obronov, Highly efficient $2 \mu \mathrm{m}$ CW and Q-switched $\mathrm{Tm}^{3+}: \mathrm{Lu}_{2} \mathrm{O}_{3}$ ceramics lasers in-band pumped by a Raman-shifted erbium fiber laser at $1670 \mathrm{~nm}$, Opt. Lett. 41 (10) (2016) 2298-2301.

[14] W. Yao, F. Wu, Y. Zhao, H. Chen, X. Xu, D. Shen, Highly efficient Tm:CaYAlO 4 laser in-band pumped by a Raman fiber laser at $1.7 \mu$ m, Appl. Optic. 55 (14) (2016) 3730-3733.

[15] P. Loiko, R. Thouroude, R. Soulard, L. Guillemot, G. Brasse, B. Guichardaz, A. Braud, A. Hideur, M. Laroche, H. Gilles, P. Camy, In-band pumping of Tm:LiYF 4 channel waveguide: a power scaling strategy for $\sim 2 \mu \mathrm{m}$ waveguide lasers, Opt. Lett. 44 (12) (2019) 3010-3013.

[16] S. Rivier, X. Mateos, V. Petrov, U. Griebner, Y.E. Romanyuk, C.N. Borca, F. Gardillou, M. Pollnau, Tm:KY(WO 4$)_{2}$ waveguide laser, Optic Express 15 (9) (2007) 5885-5892.

[17] W. Bolaños, J.J. Carvajal, X. Mateos, E. Cantelar, G. Lifante, U. Griebner, V. Petrov, V.L. Panyutin, G.S. Murugan, J.S. Wilkinson, M. Aguiló, F. Díaz, Continuouswave and Q-switched Tm-doped $\mathrm{KY}\left(\mathrm{WO}_{4}\right)_{2}$ planar waveguide laser at $1.84 \mu \mathrm{m}$, Optic Express 19 (2) (2011) $1449-1454$.

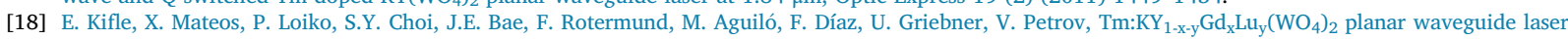
passively Q-switched by single-walled carbon nanotubes, Optic Express 26 (4) (2018) 4961-4966.

[19] K. van Dalfsen, S. Aravazhi, D. Geskus, K. Wörhoff, M. Pollnau, Efficient $\mathrm{KY}_{1-\mathrm{x}-\mathrm{y}} \mathrm{Gd}_{\mathrm{x}} \mathrm{Lu}_{\mathrm{y}}\left(\mathrm{WO}_{4}\right)_{2}$ :Tm ${ }^{3+}$ channel waveguide lasers, Optic Express 19 (6) (2011) $5277-5282$.

[20] P. Loiko, R. Soulard, G. Brasse, J.-L. Doualan, B. Guichardaz, A. Braud, A. Tyazhev, A. Hideur, P. Camy, Watt-level Tm:LiYF 4 channel waveguide laser produced by diamond saw dicing, Optic Express 26 (19) (2018) 24653-24662.

[21] E. Kifle, P. Loiko, U. Griebner, V. Petrov, P. Camy, A. Braud, M. Aguiló, F. Díaz, X. Mateos, Diamond saw dicing of thulium channel waveguide lasers in monoclinic crystalline films, Opt. Lett. 44 (7) (2019) 1596-1599.

[22] J.I. Mackenzie, S.C. Mitchell, R.J. Beach, H.E. Meissner, D.P. Shepherd, 15 W diode-side-pumped Tm:YAG waveguide laser at 2 um, Electron. Lett. 37 (14) (2001) 898-899.

[23] D.P. Shepherd, D.J.B. Brinck, J. Wang, A.C. Tropper, D.C. Hanna, G. Kakarantzas, P.D. Townsend, 1.9- $\mu$ m operation of a Tm:lead germanate glass waveguide laser, Opt. Lett. 19 (13) (1994) 954-956.

[24] N. Li, P. Purnawirman, Z. Su, E.S. Magden, P.T. Callahan, K. Shtyrkova, M. Xin, A. Ruocco, C. Baiocco, E.P. Ippen, F.X. Kärtner, J.D.B. Bradley, D. Vermeulen, M.R. Watts, High-power thulium lasers on a silicon photonics platform, Opt. Lett. 42 (6) (2017) 1181-1184.

[25] R.R. Gattass, E. Mazur, Femtosecond laser micromachining in transparent materials, Nat. Photon. 2 (4) (2008) 219.

[26] K.M. Davis, K. Miura, N. Sugimoto, K. Hirao, Writing waveguides in glass with a femtosecond laser, Opt. Lett. 21 (21) (1996) $1729-1731$.

[27] D.G. Lancaster, S. Gross, H. Ebendorff-Heidepriem, K. Kuan, T.M. Monro, M. Ams, A. Fuerbach, M.J. Withford, Fifty percent internal slope efficiency femtosecond direct-written $\mathrm{Tm}^{3+}$ :ZBLAN waveguide laser, Opt. Lett. 36 (9) (2011) 1587-1589.

[28] D.G. Lancaster, S. Gross, A. Fuerbach, H.E. Heidepriem, T.M. Monro, M.J. Withford, Versatile large-mode-area femtosecond laser-written Tm:ZBLAN glass chip lasers, Optic Express 20 (25) (2012) 27503-27509.

[29] Y. Ren, G. Brown, A. Ródenas, S. Beecher, F. Chen, A.K. Kar, Mid-infrared waveguide lasers in rare-earth-doped YAG, Opt. Lett. 37 (16) (2012) 3339-3341.

[30] J. Morris, N.K. Stevenson, H.T. Bookey, A.K. Kar, C.T.A. Brown, J.-M. Hopkins, M.D. Dawson, A.A. Lagatsky, 1.9 m waveguide laser fabricated by ultrafast laser inscription in Tm: $\mathrm{Lu}_{2} \mathrm{O}_{3}$ ceramic, Optic Express 25 (13) (2017) 14910-14917.

[31] E. Kifle, P. Loiko, J.R.V. de Aldana, C. Romero, A. Ródenas, S.Y. Choi, J.E. Bae, F. Rotermund, V. Zakharov, A. Veniaminov, M. Aguiló, F. Díaz, U. Griebner, V. Petrov, X. Mateos, Passively Q-switched femtosecond-laser-written thulium waveguide laser based on evanescent field interaction with carbon nanotubes, Photon. Res. 6 (10) (2018) 971-980.

[32] E. Kifle, P. Loiko, X. Mateos, J.R.V. de Aldana, A. Ródenas, U. Griebner, V. Petrov, M. Aguiló, F. Díaz, Femtosecond-laser-written hexagonal cladding waveguide in Tm:KLu(WO$\left.)_{2}\right)_{2}: \mu$-Raman study and laser operation, Opt. Mater. Express 7 (12) (2017) 4258-4268. 


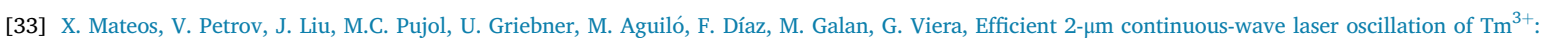
$\mathrm{KLu}\left(\mathrm{WO}_{4}\right)_{2}$, IEEE J. Quant. Electron. 42 (10) (2006) 1008-1015.

[34] J.M. Serres, X. Mateos, P. Loiko, K. Yumashev, N. Kuleshov, V. Petrov, U. Griebner, M. Aguiló, F. Díaz, Diode-pumped microchip Tm:KLu(WO 4$)_{2}$ laser with more than 3 W of output power, Opt. Lett. 39 (14) (2014) 4247-4250.

[35] M. Segura, M. Kadankov, X. Mateos, M.C. Pujol, J.J. Carvajal, M. Aguiló, F. Díaz, U. Griebner, V. Petrov, Passive Q-switching of the diode pumped Tm ${ }^{3+}$ $\mathrm{KLu}\left(\mathrm{WO}_{4}\right)_{2}$ laser near 2- $\mu \mathrm{m}$ with $\mathrm{Cr}^{2+}: \mathrm{ZnS}$ saturable absorbers, Optic Express 20 (4) (2012) 3394-3400.

[36] P. Loiko, J.M. Serres, X. Mateos, K. Yumashev, A. Yasukevich, V. Petrov, U. Griebner, M. Aguiló, F. Díaz, Subnanosecond Tm:KLuW microchip laser Q-switched by a Cr:ZnS saturable absorber, Opt. Lett. 40 (22) (2015) 5220-5223.

[37] J.M. Serres, P. Loiko, X. Mateos, K. Yumashev, U. Griebner, V. Petrov, M. Aguiló, F. Díaz, Tm:KLu(WO 4$)_{2}$ microchip laser Q-switched by a graphene-based saturable absorber, Optic Express 23 (11) (2015) 14108-14113.

[38] A. Schmidt, S.Y. Choi, D.I. Yeom, F. Rotermund, X. Mateos, M. Segura, F. Diaz, V. Petrov, U. Griebner, Femtosecond pulses near 2 um from a Tm:KLuW laser mode-locked by a single-walled carbon nanotube saturable absorber, APEX 5 (9) (2012), 092704-1-3.

[39] S. Vatnik, I. Vedin, M. Segura, X. Mateos, M.C. Pujol, J.J. Carvajal, M. Aguiló, F. Díaz, V. Petrov, U. Griebner, Efficient thin-disk Tm-laser operation based on Tm: $\mathrm{KLu}\left(\mathrm{WO}_{4}\right)_{2} / \mathrm{KLu}\left(\mathrm{WO}_{4}\right)_{2}$ epitaxies, Opt. Lett. 37 (3) (2012) 356-358.

[40] A.A. Lagatsky, N.V. Kuleshov, V.P. Mikhailov, Diode-pumped CW lasing of Yb:KYW and Yb:KGW, Optic Commun. 165 (1-3) (1999) 71-75.

[41] J. Liu, V. Petrov, X. Mateos, H. Zhang, J. Wang, Efficient high-power laser operation of Yb:KLu(WO 4$)_{2}$ crystals cut along the principal optical axes, Opt. Lett. 32 (14) (2007) 2016-2018.

[42] P. Loiko, J.M. Serres, X. Mateos, K. Yumashev, A. Yasukevich, V. Petrov, U. Griebner, M. Aguiló, F. Díaz, Sub-nanosecond Yb:KLu(WO4)2 microchip laser, Opt. Lett. 41 (11) (2016) 2620-2623.

[43] J.M. Serres, P. Loiko, X. Mateos, K. Yumashev, N. Kuleshov, V. Petrov, U. Griebner, M. Aguiló, F. Díaz, Prospects of monoclinic Yb:KLu(WO 4$)_{2}$ crystal for multiwatt microchip lasers, Opt. Mater. Express 5 (3) (2015) 661-667.

[44] U. Griebner, S. Rivier, V. Petrov, M. Zorn, G. Erbert, M. Weyers, X. Mateos, M. Aguiló, J. Massons, F. Díaz, Passively mode-locked Yb:KLu(WO $)_{2}$ oscillators, Optic Express 13 (9) (2005) 3465-3470.

[45] M.S. Gaponenko, P.A. Loiko, N.V. Gusakova, K.V. Yumashev, N.V. Kuleshov, A.A. Pavlyuk, Thermal lensing and microchip laser performance of $N_{\mathrm{g}-\text { cut Tm }}{ }^{3+}$ : $\mathrm{KY}\left(\mathrm{WO}_{4}\right)_{2}$ crystal, Appl. Phys. B 108 (3) (2012) 603-607.

[46] P. Loiko, J.M. Serres, X. Mateos, K. Yumashev, N. Kuleshov, V. Petrov, U. Griebner, M. Aguiló, F. Díaz, In-band-pumped Ho:KLu(WO 4$)_{2}$ microchip laser with 84\% slope efficiency, Opt. Lett. 40 (3) (2015) 344-347.

[47] V. Jambunathan, X. Mateos, P.A. Loiko, J.M. Serres, U. Griebner, V. Petrov, K.V. Yumashev, M. Aguiló, F. Díaz, Growth, spectroscopy and laser operation of Ho: $\mathrm{KY}\left(\mathrm{WO}_{4}\right)_{2}$, J. Lumin. 179 (2016) 50-58.

[48] P. Loiko, J.M. Serres, X. Mateos, K. Yumashev, N. Kuleshov, V. Petrov, U. Griebner, M. Aguiló, F. Díaz, Microchip laser operation of Tm,Ho:KLu(WO 4$)_{2}$ crystal, Optic Express 22 (23) (2014) 27976-27984.

[49] X. Mateos, S. Lamrini, K. Scholle, P. Fuhrberg, S. Vatnik, P. Loiko, I. Vedin, M. Aguiló, F. Díaz, U. Griebner, V. Petrov, Holmium thin-disk laser based on Ho:

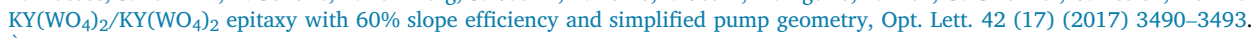

[50] Ò. Silvestre, J. Grau, M.C. Pujol, J. Massons, M. Aguiló, F. Díaz, M.T. Borowiec, A. Szewczyk, M. Urszula Gutowska, M. Massot, A. Salazar, V. Petrov, Thermal properties of monoclinic $\mathrm{KLu}\left(\mathrm{WO}_{4}\right)_{2}$ as a promising solid state laser host, Optic Express 16 (7) (2008) 5022-5034.

[51] P.A. Loiko, X. Mateos, N.V. Kuleshov, A.A. Pavlyuk, K.V. Yumashev, V. Petrov, U. Griebner, M. Aguiló, F. Díaz, Thermal-lens-driven effects in Ng-cut Yb-and Tmdoped monoclinic KLu(WO$)_{2}$ crystals, IEEE J. Quant. Electron. 50 (8) (2014) 669-676.

[52] P.A. Loiko, K.V. Yumashev, N.V. Kuleshov, A.A. Pavlyuk, Thermal lensing study and athermal directions in flashlamp-pumped Nd:KGd(WO $)_{2}$ laser crystal, Appl. Phys. B 106 (4) (2012) 881-886.

[53] P.A. Loiko, K.V. Yumashev, N.V. Kuleshov, G.E. Rachkovskaya, A.A. Pavlyuk, Thermo-optic dispersion formulas for monoclinic double tungstates KRe(WO 4$)_{2}$ where Re = Gd, Y, Lu, Yb, Opt. Mater. 33 (11) (2011) 1688-1694.

[54] P.A. Loiko, K.V. Yumashev, N.V. Kuleshov, G.E. Rachkovskaya, A.A. Pavlyuk, Detailed characterization of thermal expansion tensor in monoclinic KRe(WO 4$)_{2}$ (where Re = Gd, Y, Lu, Yb), Opt. Mater. 34 (1) (2011) 23-26.

[55] P.A. Loiko, J.M. Serres, X. Mateos, K.V. Yumashev, N.V. Kuleshov, V. Petrov, U. Griebner, M. Aguiló, F. Díaz, Characterization of the thermal lens in 3 at.\% Tm: $\mathrm{KLu}\left(\mathrm{WO}_{4}\right)_{2}$ and microchip laser operation, Laser Phys. Lett. 11 (7) (2014), 075001-1-7.

[56] P.A. Loiko, J.M. Serres, X. Mateos, K.V. Yumashev, N.V. Kuleshov, V. Petrov, U. Griebner, M. Aguiló, F. Díaz, Thermal lensing in Yb:KLu(WO $)_{2}$ crystals cut along the optical indicatrix axes, Laser Phys. Lett. 11 (12) (2014), 125802-1-6.

[57] P.A. Loiko, S. Manjooran, K.V. Yumashev, A. Major, Polarization-anisotropy of thermal lens in $\mathrm{Yb}_{\mathrm{K}} \mathrm{KY}_{\left(\mathrm{WO}_{4}\right)_{2}}$ laser crystal under high-power diode pumping, Appl. Optic. 56 (10) (2017) 2937-2945.

[58] K. Yumashev, P. Loiko, Thermal stress and end-bulging in monoclinic crystals: the case study of double tungstates, Appl. Optic. 56 (13) (2017) 3857-3866.

[59] P.A. Loiko, V.V. Filippov, K.V. Yumashev, N.V. Kuleshov, A.A. Pavlyuk, All-space existence and dispersion of athermal directions in monoclinic KY(WO4)2, Optic Commun. 326 (2014) 144-149.

[60] E. Kifle, X. Mateos, J.R. Vázquez de Aldana, A. Ródenas, P. Loiko, S.Y. Choi, F. Rotermund, U. Griebner, V. Petrov, M. Aguiló, F. Díaz, Femtosecond-laser written Tm:KLu(WO $)_{2}$ waveguide lasers, Opt. Lett. 42 (6) (2017) 1169-1172.

[61] T.C. Damen, S.P.S. Porto, B. Tell, Raman effect in zinc oxide, Phys. Rev. 142 (2) (1966) 570-574.

[62] H.-D. Nguyen, A. Ródenas, J.R. Vázquez de Aldana, J. Martínez, F. Chen, M. Aguiló, M.C. Pujol, F. Díaz, Heuristic modelling of laser written mid-infrared $\mathrm{LiNbO}_{3}$ stressed-cladding waveguides, Optic Express 24 (7) (2016) 7777-7791.

[63] K.V. Yumashev, A.N. Zakharova, P.A. Loiko, Photo-elastic effect, thermal lensing and depolarization in a-cut tetragonal laser crystals, Laser Phys. 26 (6) (2016) $1-10,065002$.

[64] P. Loiko, P. Segonds, P.L. Inácio, A. Peña, J. Debray, D. Rytz, V. Filippov, K. Yumashev, M.C. Pujol, X. Mateos, M. Aguiló, F. Díaz, M. Eichhorn, B. Boulanger, Refined orientation of the optical axes as a function of wavelength in three monoclinic double tungstate crystals $\left.\mathrm{KRE}_{(\mathrm{WO}}\right)_{2}(\mathrm{RE}=\mathrm{Gd}$, Y or Lu), Opt. Mater. Express 6 (9) (2016) 2984-2990.

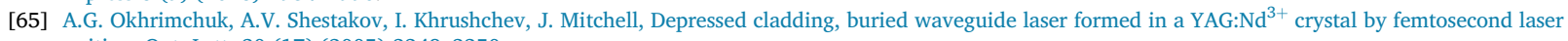
writing, Opt. Lett. 30 (17) (2005) 2248-2250.

[66] A. Okhrimchuk, V. Mezentsev, A. Shestakov, Bennion, Low loss depressed cladding waveguide inscribed in YAG:Nd single crystal by femtosecond laser pulses, Optic Express 20 (4) (2012) 3832-3843.

[67] H. Liu, Y. Jia, F. Chen, J.R. Vázquez de Aldana, Continuous wave laser operation in Nd:GGG depressed tubular cladding waveguides produced by inscription of femtosecond laser pulses, Opt. Mater. Express 3 (2) (2013) 278-283.

[68] A.G. Okhrimchuk, P.A. Obraztsov, 11-GHz waveguide Nd: YAG laser CW mode-locked with single-layer graphene, Sci. Rep. 5 (1) (2015) 11172.

[69] H. Liu, Y. Jia, J.R.V. de Aldana, D. Jaque, F. Chen, Femtosecond laser inscribed cladding waveguides in Nd:YAG ceramics: fabrication, fluorescence imaging and laser performance, Optic Express 20 (17) (2012) 18620-18629.

[70] Gabriela Salamu, Florin Jipa, Marian Zamfirescu, Nicolaie Pavel, Laser emission from diode-pumped Nd:YAG ceramic waveguide lasers realized by direct femtosecond-laser writing technique, Optic Express 22 (5) (2014) 5177-5182.

[71] N. Pavel, G. Salamu, F. Jipa, M. Zamfirescu, Diode-laser pumping into the emitting level for efficient lasing of depressed cladding waveguides realized in Nd: $\mathrm{YVO}_{4}$ by the direct femtosecond-laser writing technique, Optic Express 22 (19) (2014) 23057-23065.

[72] Y. Jia, J.R.V. de Aldana, F. Chen, Efficient waveguide lasers in femtosecond laser inscribed double-cladding waveguides of Yb:YAG ceramics, Opt. Mater. Express 3 (5) (2013) 645-650.

[73] G. Palmer, S. Gross, A. Fuerbach, D.G. Lancaster, M.J. Withford, High slope efficiency and high refractive index change in direct-written Yb-doped waveguide lasers with depressed claddings, Optic Express 21 (14) (2013) 17413-17420. 
[74] Yi Ren, C. Cheng, Y. Jia, Y. Jiao, D. Li, M.D. Mackenzie, A.K. Kar, F. Chen, Switchable single-dual-wavelength Yb,Na:CaF 2 waveguide lasers operating in continuous-wave and pulsed regimes, Opt. Mater. Express 8 (6) (2018) 1633-1641.

[75] F. Moglia, S. Müller, F. Reichert, P.W. Metz, T. Calmano, C. Kränkel, E. Heumann, G. Huber, Efficient upconversion-pumped continuous wave Er ${ }^{3+}$ :LiLuF 4 lasers, Opt. Mater. 42 (2015) 167-173.

[76] C. Khurmi, N.B. Hébert, W.Q. Zhang, S. Afshar, G. Chen, J. Genest, T.M. Monro, D.G. Lancaster, Ultrafast pulse generation in a mode-locked Erbium chip waveguide laser, Optic Express 24 (24) (2016) 27177-27183.

[77] D.G. Lancaster, Y. Li, Y. Duan, S. Gross, M.W. Withford, T.M. Monro, Er ${ }^{3+}$ active $\mathrm{Yb}^{3+} \mathrm{Ce}^{3+}$ co-doped fluorozirconate guided-wave chip lasers, IEEE Photon. Technol. Lett. 28 (21) (2016) 2315-2318.

[78] H. Liu, S. Luo, B. Xu, H. Xu, Z. Cai, M. Hong, P. Wu, Femtosecond-laser micromachined Pr:YLF depressed cladding waveguide: Raman, fluorescence, and laser performance, Opt. Mater. Express 7 (11) (2017) 3990-3997.

[79] C. Khurmi, S. Thoday, T.M. Monro, G. Chen, D.G. Lancaster, Visible laser emission from a praseodymium-doped fluorozirconate guided-wave chip, Opt. Lett. 42 (17) (2017) 3339-3342.

[80] D.G. Lancaster, S. Gross, H. Ebendorff-Heidepriem, M.J. Withford, T.M. Monro, S.D. Jackson, Efficient 2.9 m fluorozirconate glass waveguide chip laser, Opt. Lett. 38 (14) (2013) 2588-2591.

[81] D.G. Lancaster, S. Gross, H. Ebendorff-Heidepriem, A. Fuerbach, M.J. Withford, T.M. Monro, $2.1 \mu$ m waveguide laser fabricated by femtosecond laser directwriting in $\mathrm{Ho}^{3+}, \mathrm{Tm}^{3+}$ :ZBLAN glass, Opt. Lett. 37 (6) (2012) 996-998.

[82] S. McDaniel, F. Thorburn, A. Lancaster, R. Stites, G. Cook, A. Kar, Operation of Ho:YAG ultrafast laser inscribed waveguide lasers, Appl. Optic. 56 (12) (2017) 3251-3256.

[83] A.G. Okhrimchuk, V.K. Mezentsev, V.V. Dvoyrin, A.S. Kurkov, E.M. Sholokhov, S.K. Turitsyn, A.V. Shestakov, I. Bennion, Waveguide-saturable absorber fabricated by femtosecond pulses in YAG: $\mathrm{Cr}^{4+}$ crystal for Q-switched operation of Yb-fiber laser, Opt. Lett. 34 (24) (2009) $3881-3883$.

[84] J.R. Macdonald, S.J. Beecher, P.A. Berry, G. Brown, K.L. Schepler, A.K. Kar, Efficient mid-infrared Cr:ZnSe channel waveguide laser operating at 2486 nm, Opt. Lett. 38 (13) (2013) 2194-2196.

[85] A. Lancaster, G. Cook, S.A. McDaniel, J. Evans, P.A. Berry, J.D. Shephard, A.K. Kar, Mid-infrared laser emission from Fe: ZnSe cladding waveguides, Appl. Phys. Lett. 107 (3) (2015), 031108-1-4.

[86] R. Thouroude, H. Gilles, B. Cadier, T. Robin, A. Hideur, A. Tyazhev, R. Soulard, P. Camy, J.L. Doualan, M. Laroche, Linearly-polarized high-power Raman fiber lasers near $1670 \mathrm{~nm}$, Laser Phys. Lett. 16 (2) (2019), 025102-1-5.

[87] T.-Y. Tsai, M. Birnbaum, Q-switched 2- $\mu \mathrm{m}$ lasers by use of a $\mathrm{Cr}^{2+}$ :ZnSe saturable absorber, Appl. Optic. 40 (36) (2001) $6633-6637$.

[88] H. Yu, V. Petrov, U. Griebner, D. Parisi, S. Veronesi, M. Tonelli, Compact passively Q-switched diode-pumped Tm:LiLuF 4 laser with 1.26 mJ output energy, Opt. Lett. 37 (13) (2012) 2544-2546.

[89] R. Faoro, M. Kadankov, D. Parisi, S. Veronesi, M. Tonelli, V. Petrov, U. Griebner, M. Segura, X. Mateos, Passively Q-switched Tm:YLF laser, Opt. Lett. 37 (9) (2012) 1517-1519.

[90] S.B. Mirov, V.V. Fedorov, D. Martyshkin, I.S. Moskalev, M. Mirov, S. Vasilyev, "Progress in mid-IR lasers based on Cr and Fe-doped II-VI chalcogenides, IEEE J. Sel. Top. Quant. Electron. 21 (1) (2014) 292-310.

[91] I.T. Sorokina, "Cr ${ }^{2+}$-doped II-VI materials for lasers and nonlinear optics, Opt. Mater. 26 (4) (2004) $395-412$.

[92] P. Loiko, V. Vitkin, S. Balabanov, O. Dymshits, K. Grigorenko, A. Polishchuk, A. Volokitina, X. Mateos, J.M. Serres, E. Gavrishchuk, Saturable absorption properties at $1.54 \mu \mathrm{m}$ of $\mathrm{Cr}^{2+}: \mathrm{ZnS}$ prepared by thermal diffusion at hot isostatic pressing, Laser Phys. Lett. 16 (6) (2019), 065801-1-6.

[93] P. Loiko, X. Mateos, S.Y. Choi, F. Rotermund, J.M. Serres, M. Aguiló, F. Díaz, K. Yumashev, U. Griebner, V. Petrov, Vibronic thulium laser at 2131 nm Q switched by single-walled carbon nanotubes, J. Opt. Soc. Am. B 33 (11) (2016) D19-D27.

[94] F. Cornacchia, D. Parisi, C. Bernardini, A. Toncelli, M. Tonelli, Efficient, diode-pumped Tm ${ }^{3+}: B_{2} \mathrm{~F}_{8}$ vibronic laser, Optic Express 12 (9) (2004) $1982-1989$.

[95] P. Loiko, L. Zhang, J.M. Serres, Y. Wang, M. Aguiló, F. Díaz, Z. Lin, H. Lin, G. Zhang, E. Vilejshikova, E. Dunina, A. Kornienko, L. Fomicheva, V. Petrov, U. Griebner, W. Chen, X. Mateos, Monoclinic Tm: $\mathrm{MgWO}_{4}$ crystal: crystal-field analysis, tunable and vibronic laser demonstration, J. Alloys Compd. 763 (2018) 581-591.

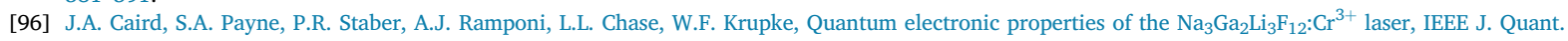
Electron. 24 (6) (1988) 1077-1099.

[97] X. Mateos, P. Loiko, J.M. Serres, K. Yumashev, U. Griebner, V. Petrov, M. Aguiló, F. Díaz, Efficient micro-lasers based on highly-doped monoclinic double tungstates, IEEE J. Quant. Electron. 53 (3) (2017), 1700110-1700111-10.

[98] P. Loiko, M. Pollnau, Stochastic model of energy-transfer processes among rare-earth ions. Example of $\mathrm{Al}_{2} \mathrm{O}_{3}: \mathrm{Tm}^{3+}$, J. Phys. Chem. C 120 (46) (2016) 26480-26489.

[99] V. Llamas, P. Loiko, E. Kifle, C. Romero, J.R.V. de Aldana, Z. Pan, J.M. Serres, H. Yuan, X. Dai, H. Cai, Y. Wang, Y. Zhao, V. Zakharov, A. Veniaminov, R. Thouroude, M. Laroche, H. Gilles, M. Aguiló, F. Díaz, U. Griebner, V. Petrov, P. Camy, X. Mateos, Ultrafast laser inscribed waveguide lasers in Tm:CALGO with depressed-index cladding, Optic Express 28 (3) (2020) 3528-3540.

[100] J.M. Serres, V. Jambunathan, P. Loiko, X. Mateos, H. Yu, H. Zhang, J. Liu, A. Lucianetti, T. Mocek, K. Yumashev, U. Griebner, V. Petrov, M. Aguiló, F. Díaz, Microchip laser operation of Yb-doped gallium garnets, Opt. Mater. Express 6 (1) (2016) 46-57.

[101] S.M. Eaton, C.A. Merchant, R. Iyer, A.J. Zilkie, A.S. Helmy, J.S. Aitchison, P.R. Herman, D. Kraemer, R.J.D. Miller, C. Hnatovsky, R.S. Taylor, Raman gain from waveguides inscribed in $\mathrm{KGd}\left(\mathrm{WO}_{4}\right)_{2}$ by high repetition rate femtosecond laser, Appl. Phys. Lett. 92 (8) (2008), 081105-1-3.

[102] F.M. Bain, A.A. Lagatsky, R.R. Thomson, N.D. Psaila, N.V. Kuleshov, A.K. Kar, W. Sibbett, C.T.A. Brown, Ultrafast laser inscribed Yb:KGd(WO $)_{2}$ and Yb: $\mathrm{KY}\left(\mathrm{WO}_{4}\right)_{2}$ channel waveguide lasers, Optic Express 17 (25) (2009) 22417-22422.

[103] F.M. Bain, W.F. Silva, A.A. Lagatsky, R.R. Thomson, N.D. Psaila, A.K. Kar, W. Sibbett, D. Jaque, C.T.A. Brown, Microspectroscopy of ultrafast laser inscribed channel waveguides in Yb:tungstate crystals, Appl. Phys. Lett. 98 (14) (2011) 141108.

[104] C.N. Borca, V. Apostolopoulos, F. Gardillou, H.G. Limberger, M. Pollnau, R.P. Salathé, Buried channel waveguides in Yb-doped KY(WO $)_{2}$ crystals fabricated by femtosecond laser irradiation, Appl. Surf. Sci. 253 (19) (2007) 8300-8303.

[105] J.M. de Mendívil, J. del Hoyo, J. Solís, M.C. Pujol, M. Aguiló, F. Díaz, G. Lifante, Mirrorless Yb ${ }^{3+}$-doped monoclinic double tungstate waveguide laser combining liquid phase epitaxy and multiplexed beam fs laser writing, J. Lightwave Technol. 33 (23) (2015) 4726-4730.

[106] J.M. de Mendivil, J. Hoyo, J. Solis, M.C. Pujol, M. Aguiló, F. Diaz, G. Lifante, Channel waveguide fabrication in KY(WO 4$)_{2}$ combining liquid-phase-epitaxy and beam-multiplexed femtosecond laser writing, Opt. Mater. 47 (2015) 304-309.

[107] J. E. Bae, T. G. Park, E. Kifle, X. Mateos, M. Aguiló, F. Díaz, C. Romero, J. R. V. de Aldana, and F. Rotermund, "Yb:KLuW channel waveguide lasers passively Qswitched by evanescent-field interaction with carbon nanotubes," in 2019 Conference on Lasers and Electro-Optics Europe and European Quantum Electronics Conference, OSA Technical Digest (Optical Society of America, 2019), P. ca_3_2.

[108] X. Liu, S. Qu, Y. Tan, C. Zhang, F. Chen, Buried channel waveguides in neodymium-doped $\left.\mathrm{KGd}_{(\mathrm{WO}}\right)_{2}$ fabricated by low-repetition-rate femtosecond laser writing, Appl. Phys. B 103 (1) (2011) 145-149.

[109] X. Liu, S. Qu, Y. Tan, F. Chen, Preservation of fluorescence and Raman gain in the buried channel waveguides in neodymium-doped KGd(WO $)_{2}\left(\mathrm{Nd}_{\mathrm{K}} \mathrm{KGW}\right)$ by femtosecond laser writing, Appl. Optic. 50 (6) (2011) 930-934.

[110] H. Liu, Q. An, F. Chen, J.R.V. de Aldana, B. del Rosal Rabes, Continuous-wave lasing at $1.06 \mu \mathrm{m}$ in femtosecond laser written Nd:KGW waveguides, Opt. Mater. 37 (2014) 93-96.

[111] E. Kifle, P. Loiko, C. Romero, J.R.V. de Aldana, A. Ródenas, V. Jambunathan, V. Zakharov, A. Veniaminov, A. Lucianetti, T. Mocek, M. Aguiló, F. Díaz, U. Griebner, V. Petrov, X. Mateos, Fs-laser-written erbium-doped double tungstate waveguide laser, Optic Express 26 (23) (2018) $30826-30836$.

[112] E. Kifle, P. Loiko, J.R.V. de Aldana, C. Romero, A. Ródenas, V. Zakharov, A. Veniaminov, H. Yu, H. Zhang, Y. Chen, M. Aguiló, F. Díaz, U. Griebner, V. Petrov, X. Mateos, Fs-laser-written thulium waveguide lasers Q-switched by graphene and MoS 2 , Optic Express 27 (6) (2019) $8745-8755$. 
[113] E. Kifle, P. Loiko, C. Romero, J.R.V. de Aldana, A. Ródenas, V. Zakharov, A. Veniaminov, M. Aguiló, F. Díaz, U. Griebner, V. Petrov, X. Mateos, Femtosecondlaser-written $\mathrm{Ho}: \mathrm{KGd}\left(\mathrm{WO}_{4}\right)_{2}$ waveguide laser at $2.1 \mu \mathrm{m}$, Opt. Lett. 44 (7) (2019) 1738-1741.

[114] A.E. Siegman, Lasers, Univ. Sci. Books, Mill Valley, CA, 1986, pp. 1024-1028.

[115] S. Chénais, F. Balembois, F. Druon, G. Lucas-Leclin, P. Georges, Thermal lensing in diode-pumped ytterbium lasers-part II: evaluation of quantum efficiencies and thermo-optic coefficients, IEEE J. Quant. Electron. 40 (9) (2004) 1235-1243.

[116] J.M. Serres, P.A. Loiko, X. Mateos, V. Jambunathan, A.S. Yasukevich, K.V. Yumashev, V. Petrov, U. Griebner, M. Aguiló, F. Díaz, Passive Q-switching of Tm,Ho: $\mathrm{KLu}\left(\mathrm{WO}_{4}\right)_{2}$ microchip laser by a Cr:ZnS saturable absorber, Appl. Optic. 55 (14) (2016) 3757-3763.

[117] R. Lan, P. Loiko, X. Mateos, Y. Wang, J. Li, Y. Pan, S.Y. Choi, M.H. Kim, F. Rotermund, A. Yasukevich, K. Yumashev, U. Griebner, V. Petrov, Passive Q-switching of microchip lasers based on Ho:YAG ceramics, Appl. Optic. 55 (18) (2016) 4877-4887.

[118] E. Kifle, X. Mateos, P. Loiko, K. Yumashev, A. Yasukevich, V. Petrov, U. Griebner, M. Aguiló, F. Díaz, Graphene Q-switched Tm:KY(WO 4$)_{2}$ waveguide laser, Laser Phys. 27 (4) (2017), 045801-1-6.

[119] P. Loiko, J.M. Serres, S.S. Delekta, E. Kifle, J. Bogusławski, M. Kowalczyk, J. Sotor, M. Aguiló, F. Díaz, U. Griebner, V. Petrov, S. Popov, J. Li, X. Mateos, M. Östling, Inkjet-printing of graphene saturable absorbers for $\sim 2 \mu \mathrm{m}$ bulk and waveguide lasers, Opt. Mater. Express 8 (9) (2018) $2803-2814$.

[120] J.H. Lee, S. Gross, B.V. Cunning, C.L. Brown, D. Kielpinski, T.M. Monro, D.G. Lancaster, Graphene-based passive Q-switching of a Tm ${ }^{3+}$ :ZBLAN short-infrared waveguide laser, in: Conference on Lasers and Electro-Optics (CLEO), IEEE, 2014. JTu4A.128.

[121] X. Jiang, S. Gross, H. Zhang, Z. Guo, M.J. Withford, A. Fuerbach, Bismuth telluride topological insulator nanosheet saturable absorbers for q-switched modelocked Tm:ZBLAN waveguide lasers, Ann. Phys. 528 (7-8) (2016) 543-550.

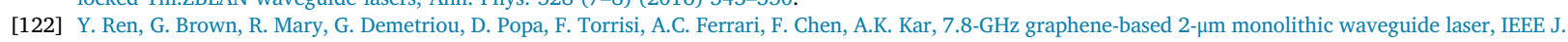
Sel. Top. Quant. Electron. 21 (1) (2015) 395-400.

[123] Q. Bao, H. Zhang, Y. Wang, Z. Ni, Y. Yan, Z.X. Shen, K.P. Loh, D.Y. Tang, Atomic-layer graphene as a saturable absorber for ultrafast pulsed lasers, Adv. Funct. Mater. 19 (19) (2009) 3077-3083.

[124] G. Xing, H. Guo, X. Zhang, T.C. Sum, C.H.A. Huan, The Physics of ultrafast saturable absorption in graphene, Optic Express 18 (5) (2010) $4564-4573$.

[125] W.B. Cho, J.H. Yim, S.Y. Choi, S. Lee, A. Schmidt, G. Steinmeyer, U. Griebner, V. Petrov, D.-I. Yeom, K. Kim, F. Rotermund, Boosting the nonlinear optical response of carbon nanotube saturable absorbers for broadband mode-locking of bulk lasers, Adv. Funct. Mater. 20 (12) (2010) $1937-1943$.

[126] S. Wang, H. Yu, H. Zhang, A. Wang, M. Zhao, Y. Chen, L. Mei, J. Wang, Broadband few-layer MoS 2 saturable absorbers, Adv. Mater. 26 (21) (2014) 3538-3544.

[127] J.M. Serres, P. Loiko, X. Mateos, H. Yu, H. Zhang, Y. Chen, V. Petrov, U. Griebner, K. Yumashev, M. Aguiló, F. Díaz, MoS 2 saturable absorber for passive Qswitching of Yb and Tm microchip lasers, Opt. Mater. Express 6 (10) (2016) 3262-3273.

[128] P. Yan, R. Lin, S. Ruan, A. Liu, H. Chen, Y. Zheng, S. Chen, C. Guo, J. Hu, A practical topological insulator saturable absorber for mode-locked fiber laser, Sci. Rep. 5 (2015) 8690.

[129] A.S. Yasukevich, P. Loiko, N.V. Gusakova, J.M. Serres, X. Mateos, K.V. Yumashev, N.V. Kuleshov, V. Petrov, U. Griebner, M. Aguiló, F. Díaz, Modeling of graphene Q-switched Tm lasers, Optic Commun. 389 (2017) 15-22.

[130] F. Zhang, S. Han, Y. Liu, Z. Wang, X. Xu, Dependence of the saturable absorption of graphene upon excitation photon energy, Appl. Phys. Lett. 106 (9) (2015), 091102.

[131] X. Mateos, P. Loiko, S.Y. Choi, F. Rotermund, M. Aguiló, F. Díaz, U. Griebner, V. Petrov, Single-walled carbon nanotubes oust graphene and semiconductor saturable absorbers in Q-switched solid-state lasers at $2 \mu \mathrm{m}$, Laser Phys. Lett. 14 (9) (2017), 095801-1-7.

[132] S.Y. Choi, T. Calmano, F. Rotermund, C. Kränkel, 2-GHz carbon nanotube mode-locked Yb:YAG channel waveguide laser, Optic Express 26 (5) (2018) $5140-5145$.

[133] Y. Jia, F. Chen, Compact solid-state waveguide lasers operating in the pulsed regime: a review [Invited], Chin. Optic Lett. 17 (1) (2019), 012302-1-01230223.

[134] C. Grivas, R. Ismaeel, C. Corbari, C.C. Huang, D.W. Hewak, P. Lagoudakis, G. Brambilla, "Generation of multi-gigahertz trains of phase-coherent femtosecond laser pulses in Ti:Sapphire waveguides, Laser Photon. Rev. 12 (11) (2018), 1800167-1-10.

[135] Z. Li, R. Li, C. Pang, N. Dong, J. Wang, H. Yu, F. Chen, 8.8 GHz Q-switched mode-locked waveguide lasers modulated by PtSe 2 saturable absorber, Optic Express 27 (6) (2019) 8727-8737.

[136] L. Guillemot, P. Loiko, R. Soulard, A. Braud, J.-L. Doualan, A. Hideur, R. Moncorgé, P. Camy, Thulium laser at $\sim 2.3 \mu$ m based on upconversion pumping, Opt. Lett. 44 (16) (2019) 4071-4074.

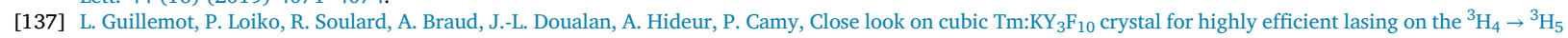
transition, Optic Express 28 (3) (2020) 3451-3463. 